\title{
Microsurgical Treatment of Craniopharyngiomas: A Retrospective Analysis
}

\author{
James Lubuulwa ${ }^{\circledR}$, Zhuang Miao, Shengwen Liu, Juan Chen, Sheng Wang, Wei Jiang, Kai Shu, \\ Ting Lei*
}

Department of Neurosurgery, Tongji Hospital of Tongji Medical College, Huazhong University of Science and Technology, Wuhan, China

Email: ${ }^{\star}$ tlei@tjh.tjmu.edu.cn

How to cite this paper: Lubuulwa, J., Miao, Z., Liu, S.W., Chen, J., Wang, S., Jiang, W., Shu, K. and Lei, T. (2020) Microsurgical Treatment of Craniopharyngiomas: A Retrospective Analysis. Open Journal of Modern Neurosurgery, 10, 427-457. https://doi.org/10.4236/ojmn.2020.104045

Received: November 21, 2019

Accepted: October 10, 2020

Published: October 13, 2020

Copyright $\odot 2020$ by author(s) and Scientific Research Publishing Inc. This work is licensed under the Creative Commons Attribution International License (CC BY 4.0).

http://creativecommons.org/licenses/by/4.0/

\begin{abstract}
Objective: This retrospective study aims to survey the clinical outcomes of 341 consecutive patients surgically treated for and diagnosed with craniopharyngioma $(\mathrm{CP})$ treated in a 10-year period in a single institution. Methods: The clinical reports of three hundred forty-one patients $\mathrm{CP}$ patients treated surgically between January 2006 and December 2016 were reviewed and analyzed retrospectively. Results: Our cohort consisted of 341 patients (202 male, 139 female) with a mean age of 34.9 years (range 1 - 74 years); Tumor Features: 129 patients $(37.8 \%)$ had cystic tumors, 88 (23.8\%) had solid tumors whereas 126 (36.4\%) had heterogeneous lesions with a solid and cystic portion; calcifications were present in 139 (40.8\%); Tumor Topography: Suprasellar 198 (58.1\%), Intrasellar 40 (11.7\%), Intra-third ventricular 103 (30.2\%); Surgical approaches used among the patients included: Pterional 262 (76.8\%), Transsphenoidal (TS) 42 (12.3\%) Transcallosal 20 (5.9\%), Transcortical 16 (4.7\%) suboccipital 1 and combined approach 1; Gross total removal (GTR) was achieved in 247 patients (72.4\%), Subtotal removal (STR) in 94 patients (27.6\%). Good postoperative outcome at discharge was achieved in 324 (95\%) patients while $17(5 \%)$ patients had poor outcome including $5(1.5 \%)$ perioperative deaths. Mean hospital length of stay was 21.87 ( 8 - 129). There were $42(12.9 \%)$ recurrences with a mean time to recurrence of 28.36 (3 - 84) months, among which 37 (88.1\%) underwent surgery for recurrence treatment. Follow-up time ranged from 3 months to 10 years. There was a statistical significance between open transcranial surgery and suprasellar tumors ( $\mathrm{p}$ $<0.0001)$, TS and intrasellar tumors $(\mathrm{p}<0.0001)$; postoperative diabetes inspidus and gross total resection $(\mathrm{p}<0.0001)$; GTR and cystic tumors $(\mathrm{p}=$ $0.034)$ calcification and GTR $(\mathrm{p}=0.0008)$. Conclusion: Good surgical outcome and long-term tumor control can be achieved through individual-based selective resection, whether total or subtotal resection. Whereas surgical pre-
\end{abstract}


history of $\mathrm{CP}$ was found to be a significant risk factor to recurrence ( $\mathrm{p}<$ 0.0001 ), the clinical risk factors of CP of recurrence are still arguable, including the presence residual tumor due to subtotal resection. More future studies are necessary.

\section{Keywords}

Craniopharyngioma, Extent of Resection, Recurrence, Retrospective

\section{Introduction}

Craniopharyngiomas (CPs) are benign tumors of the central nervous system [1] representing $1 \%$ of all the intracranial primary tumors which present with a challenging clinical and treatment sequala [2] [3] [4]. Patients usually present with visual impairments, headache, endocrine disturbances, hydrocephalus and diabetes insipidus [5]. Incidence rates stand at 2.14 (1.53 - 2.92) in children comparable to all ages at $1.86((1.60-2.14)$, with a binomial age distribution peak occurrence between 5 - 9 and 40 - 44 years [6] [7].

Histologically, CPs are categorized into two subtypes which are distinct: adamantinoumatous (ACP) and papillary (PCP) which may differ or have overlapping features in several aspects including incidence, clinical manifestation, imaging and immunohistochemical expression characteristics as reported in our previous publication [8].

Surgical treatment of $\mathrm{CP}$ has for decades been the main stay of management [9] [10] [11]. However, the main challenge lies in preservation of normal function of the pituitary-hypothalamic axis following surgery [10] [12]. Several approaches to achieve gross total resection and subtotal or partial resection have been described in published literature for CPs in various locations of the cranium [13]-[19] the most notable including pterional, transcortical, transcallosal approach, transsphenoidal (microscopic or endoscopic) approach; and the transpetrosal approach. Other invasive methods include ommaya reservoir placement [20], neuroendocopic cyst fenestration [21] [22] and ventral peritoneal shunt for CP related hydrocephalus management [23] desmopressin [24], long hormonal replacement [25] have been mentioned in clinical management of longterm morbidities. Adjuvant Radiation therapy (RT) and gamma knife surgery (GKF) have been documented to increase long time survival following subtotal resection [26] [27] [28] [29] [30]. At our institution, early studies on craniopharyngioma began in 2008 with a smaller surgical series of 43 patients by Shu Kai et al. [3] followed by a review ontreatment outcomes of transphenoidal (TS) approach for CPs by Lei Ting and associates [31] until recently followed by an update of 10 year review of TS approach for CP treatment in a cohort of 29 patients [2].

In this longitudinal study, we aimed to perform an analysis of surgical management of CP at our institution during a 10-year period between 2006 and 2016. 
We looked at clinical presentation sequela, surgical approach and postoperative outcome in long-term follow up. Furthermore we attempted to assess the predictive markers of $\mathrm{CP}$ recurrence in comparison with other large series. Finally, we proposed a simplified classification system of CP topography.

\section{Methods}

\subsection{Study Subjects and Selection Criteria}

Between January 2006 and December 2016, clinical data all adult patients (> 18 years of age) and pediatric patients who were surgically treated for and diagnosed with a primary $\mathrm{CP}$ or recurrent $\mathrm{CP}$ at our institute were collected and analayzed. The study was approved by the Institutional Review Board of Tongji Hospital of Tongji Medical College of Huazhong University of Science and Technology. Inclusion criteria were as follows: 1) surgical resection with a histopathological diagnosis of CP between 2006 and 2016;2) no past history of neurosurgical treatment other than $\mathrm{CP}$; availability of necessary clinical and radiologic data at time of acquiring data; We chose 2006 as a benchmark to let our data reflect recent advancements in microsurgery, but also offer an updated overview of our department following previously smaller studies on CP treatment [3] [31] [32]. Seventeen patients (including six children) in the records had been admitted for clinical and radiological signs and symptoms of CP but rejected surgical intervention due to generall ypoor clinical condition, or informed patient consent and these patients were excluded from this study.

\subsection{Diagnostics and Laboratory Tests}

\subsubsection{Ophthalmological and Endocrinological Evaluation}

All patients underwent ophthalmological and endocrine examination evaluation including tests of visual acuity and visual field; full endocrine panel preoperatively, at discharge and 3 months after surgery when they reported for the initial follow up reassessment.

\subsubsection{Neuroradiological Evaluation}

Preoperative examinations included CT and magnetic resonance imaging (MRI) and postoperative MRI was followed up within 48 hours in some of the patients. In some patients, only control CT was done due to patient's post-op neurological stability. Patients were advised to report for MRI reassessment three months after surgery except for patients who died in the postoperative period and those who could not be reached. Histopathological diagnosis was done after surgery by H.E staining to give a diagnosis of $\mathrm{CP}$ without further subtyping or immunohistochemical studies.

\subsection{Description of Variables Included in the Study}

The principal variables considered for each patient included: patient sex and age; presenting symptoms, past history of $\mathrm{CP}$ neurosurgery; type of surgical approach used; degree of tumor resection; CP topography, presence or absence of calcifi- 
cation and consistency; postoperative complications; postoperative outcome at hospital discharge; length of hospital stay; presence or absence of recurrence, duration of recurrence from date of operation, treatment on recurrence and surgical approach; and duration of follow-up. Tumor consistency was grouped into 3 types; cystic, mixed and solid.

\subsection{Tumor Location Hypothesis}

In 2016, our group reviewed the current literature regarding the topographical location of $\mathrm{CP}$ and found that inasmuch as several models have been proposed, there is no consensus on the appropriate model and echoed the need to develop a universally accepted system [8].

From our series, after a critical review of all the intraoperative surgical reports defining the real-time location of the tumor mass, in combination with the preoparative radiologic imaging we have attempted to propose a new classification system of CP topography. However, any attempt to perform a topographical classification requires a deep understanding of the neuroanatomical relationship [33] in the sellar region. Rhoton et al. described the sellar diaphragm as durafold covering the sella turcica in a roof-shaped manner. Though variable in different specimens, it may appear circular or convex and usually thick towards the periphery but thins out circumferentially as its breached in the middle to allow for the passage of the infundibulum [34]. This narrow opening may hypothetically explain the ease of extension of the encapsulated cystic or solid CP into the nearby regions [33].

Criteria; with the sellar diaphragm floor as the baseline the location is defined as the anatomical space which is occupied by the largest mass of the tumor tissue, without regarding the irregular tumor extensions into the proximal anatomical space, subsequently coming up with a simplification of three principal anatomical locations; suprasellar, intrasellar and intra-third ventricular (Figure 1). We considered to include another fourth category defined as ectopic location [35]-[40] although no patient qualified for this category in our data therefore was not included in the final classification. Following this classification, clinical features and surgical outcome for different tumor locations were compared.

\subsection{Surgical Treatment}

\section{Extent of Resection and Surgical Approach}

At our institution, with the recent developments in surgical techniques in the modern micro-neurosurgical era, we implement a contemporary patient-to-patient approach for the optimal choice of treatment. Our surgical principle for CP treatment was: individualized judicious resection based on the intraoperative judgement such that subtotal resection was performed in case of GTR was not achievable, with the imperative goal of preserving the hypothalamic-pituitary axis neuro-structures. Subtotal resection was defined as $\geq 90 \%$ tumor resection with remnants due to either of severe adhesions, calcifications, hard attachment to optic pathways or hypothalamus, engulfing of carotid arteries or large tumor 

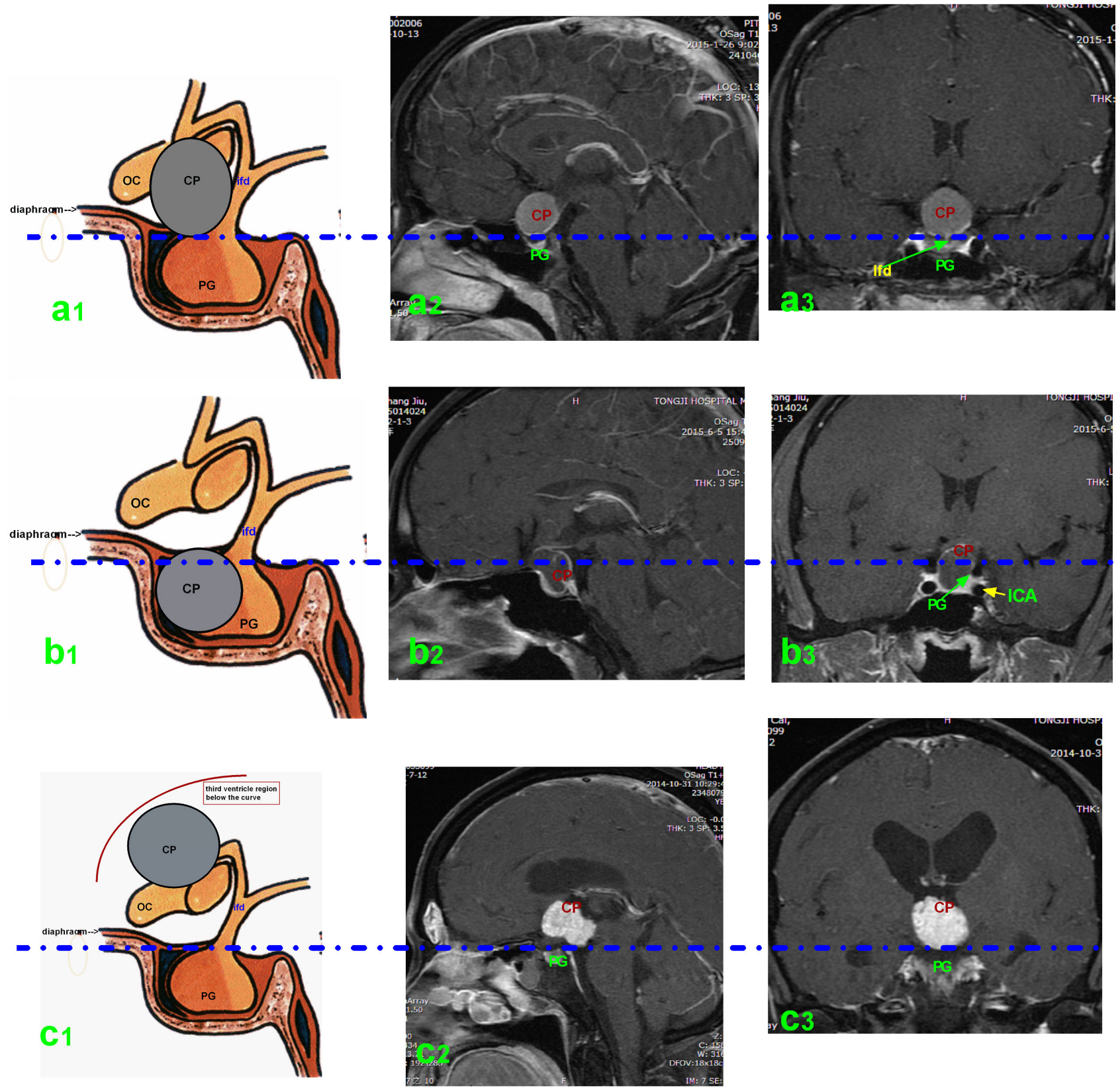

Figure 1. Showing the hypothetical locations in our simplified classification system. The dotted blue line represents the imaginary sellar floor used as the basis of topographical reference. In (a1), (b1), (c1) schematic drawings showing the neuroanatomical relationships between the tumor and the Suprasellar, Intrasellar and intra-third ventricular location respectively. (a2) sagittal section and (a3) coronal view of SS-CP, notice the intact infundibulum (green arrow). In (b2), (b3) sagittal and coronal views of IS-CP with compressed pituitary gland (PG) towards the left carotid artery. In (c2), (c3), sagittal and coronal views of the 3V-CP, with the upper floor of the third ventricle clearly eroded (arrow).

size with intended staged subresection. Additionally, the patient's age, CP topography, previous surgical approach (es) in case of RCPs, previous undertaken treatment modalities, and severity of symptoms and signs were taken into consideration when making the suitable choice of approach and extent of resection. In an attempt to verify our primary hypothesis, patients into two groups based on whether they underwent STR, or GTR, and then compared their bivariate re- 
lationships with clinical factors. There were no biopsies performed in our cohort. The decision to perform GTR or STR was made by the surgeon during the operation, based on the difficulty of each surgery. Routine postoperative control $\mathrm{CT}$ and MRI were of diagnostic purpose in confirming the presence of absence of residual tumor. The main surgical approaches adopted in our institution included pterional (PTE); transcortical-transventricular (TC-TV); transcallosal-transchoroidal (Tcall) and transsphenoidal (TS) with assisted neuroendoscopy. Similarly, the choice of the surgical approach depended solely on the surgeons' preference and preoperative images. In this cohort, radiation therapy (RT) and GKS were never prescribed as a primary treatment following surgery at our institution.

\subsection{Postoperative Outcome Assessment}

In order to determine the factors that are associated with the postoperative outcome in our surgical series, the postoperative outcome at discharge was grouped into two major categories: 1) good: total recovery without permanent neurological, hypothalamic, or neuropsychological deficits, including the presence of treatable transitory disturbances such as diabetes inspidus; 2) poor outcome: symptoms of severe hypothalamic derangement, wound infection cachexia and perioperative death. At our center, standard postoperative monitoring included treatment with adequate doses of desmopressin, dexamethasone, adequate hydration, prophylactic phenytoin, and hormonal replacement according to the deficient hormone on endocrine check-ups.

\subsection{Follow-Up Evaluations}

At our institution, the standard for follow-up evaluation starts with a first follow-up MRI, visual, endocrine, neurological and physical examination taken 3 months after surgery and was normally performed on an outpatient basis by one of the main surgeons of our neurosurgery department. Some patients were also followed up by physicians at their local referring centers and data were obtained from their medical reports. Thereafter, patients are advised to report for check up every 6 months for 2 years, and then annually or if they have any incidence of clinical symptoms related to CP. Tumor recurrence was assessed by MRI but also with concurrent clinical symptoms. For long-term follow-up data, the latest follow up was dated March 012017 for our cohort through phone call to patients or their relatives. Data which included overall survival rate and recurrence-free survival rate, and were examined and tabulated.

\subsection{Treatment Strategy for Recurrent Craniopharyngiomas (RCPs)}

A diagnosis of RCP was made based on yearly follow-up neuroimaging s findings or worsening of neurological symptoms, especially visual impairement [41]. Our strategy for RCP treatment was similar to our institutional surgical principle 
of primary CP. Additionally, the patient's age, RCP topography, previous surgical approach (es), previous undertaken treatment modalities, and severity of symptoms and signs were considered when making the suitable treatment choice.

\subsection{Statistical Analysis and Simulation}

Data were collected and entered into an excel database. Statistical analyses were performed using SPSS software (version 23, IBM Corp.). Frequencies and descriptive statistics on the various categorical variables under study were obtained. The epidemiological, clinical, and pathological variables that were relevant preoperatively and that showed significant bivariate relationships with the nominal variables were investigated by using the chi-square test or the Fisher exact test were suitable. Logistic regression was used to determine odds ratio (OR) Significance was assumed at a probability value less than 0.05 .

\section{Results}

\subsection{Demographics}

$\mathrm{CP}$ surgery is one of the routine surgeries performed given the number of patients referred to our center with an average of 30 surgeries per year.A total of 341 patients treated between 2006 and 2016 were identified (Figure 2). Among the 341 patients who underwent surgical treatment for $\mathrm{CP}$ at our institution, the mean age was 34.4 years (range 1 - 74 years). In the pediatric group, there was a

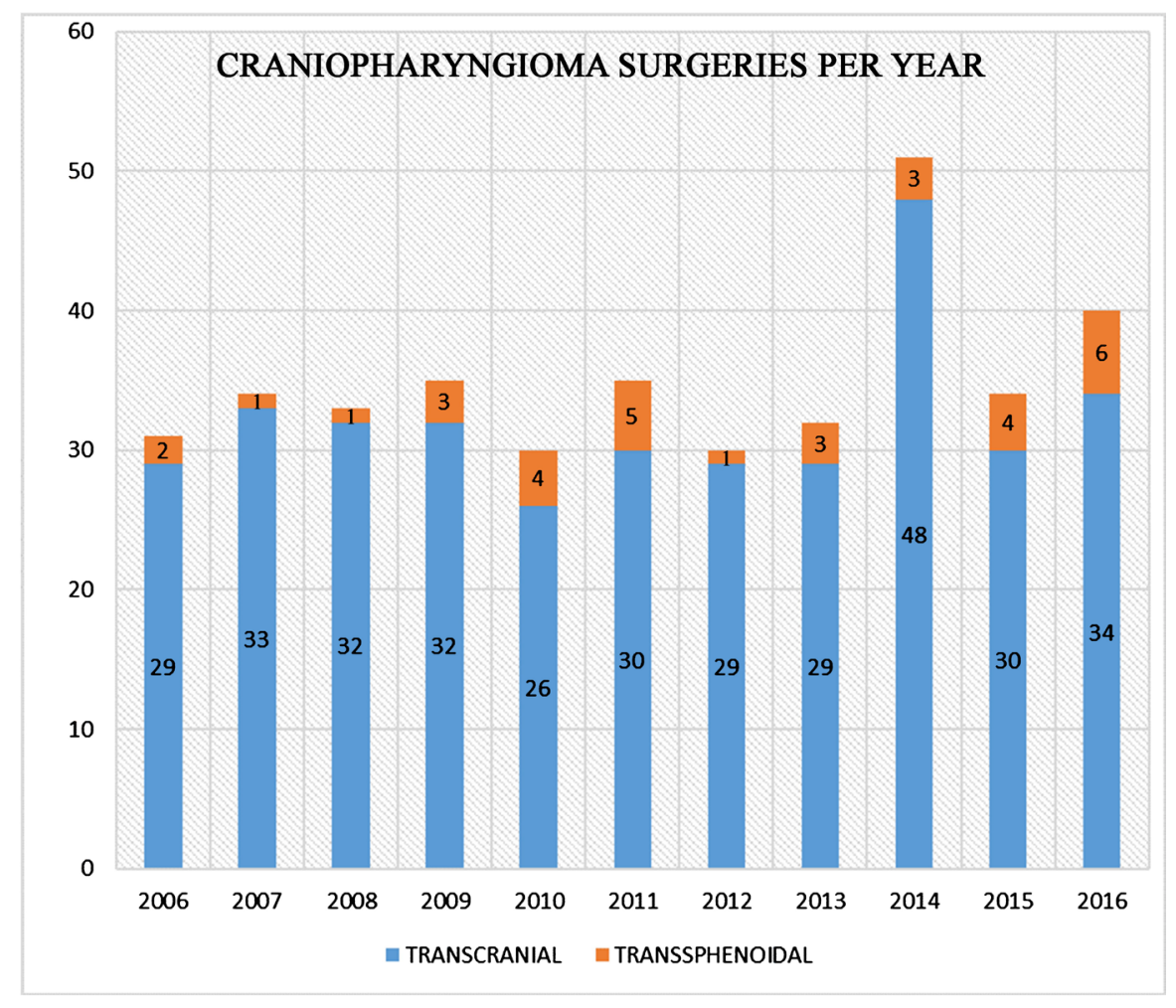

Figure 2. Showing the average number of craniopharyngioma related operations per year. 
peak incidence between 5 to 10 years, whereas the adult group showed a peak incidence was found between 46 and 51 years (Figure 3). There were sixty-nine were patients younger than 18 years at the time of surgery.

\subsection{Presenting Clinical Manifestations}

The presenting symptoms at admission are shown in Table 1 . The most frequent major presenting symptom was visual impairment (64.2\%), followed by endocrine deficiency $62.5 \%$ and headache $56.3 \%$. There was a statistically significant increased incidence of endocrine deficiencies in adult patients $(\mathrm{p}=0.017$; HR 1.928 C.I: 1.127 - 3.308). Twelve percent of the pediatric patients sought medical attention because of growth delay. Patients who presented with hydrocephalus were more likely to concurrently have nausea and vomitus significant at $\mathrm{p}<$ 0.0001 . Adult patients were more likely to present with hydrocephalus $(\mathrm{p}=$ $0.046)$ and dizziness $(\mathrm{p}<0.0001)$ than pediatric patients. In two patients, $\mathrm{CP}$ was discovered incidentally after post traumatic brain injury (TBI) imaging revealed a suprasellar lesion. These patients were treated for both TBI and after stabilizing underwent surgery for $\mathrm{CP}$ removal.

\subsection{Tumor Features}

Figure 4 summarizes the tumor characteristics in our study cohort. Tumor calcifications were observed in $40.5 \%$ of the CPs at the time of diagnosis. There was a significantly higher incidence of calcification in adult CPs $(\mathrm{p}=0.051 \mathrm{OR}=$ 0.586; CI: $0.344-0.999)$. Calcification was significantly correlated $(\mathrm{p}<0.0001)$

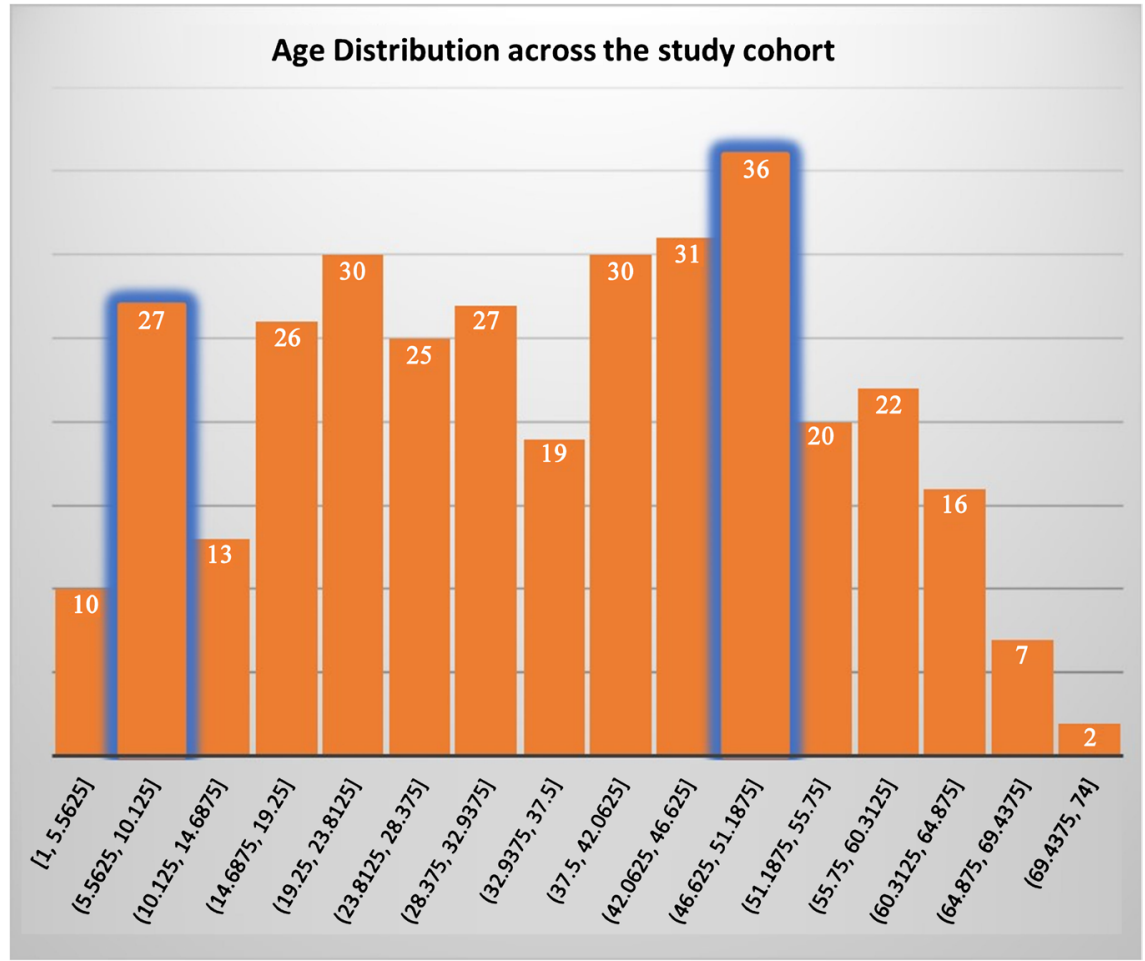

Figure 3. Showing the age distribution across the cohort in the pediatric and adult groups. 
Table 1. Showing comparison between open craniotomy and transsphenoidal approaches.

\begin{tabular}{|c|c|c|c|c|}
\hline Patient Characteristics & All Surgeries & Open Transcranial & Trans-sphenoidal & $P$ value \\
\hline Total Patients & 341 & $299(87.6 \%)$ & $42(12.3 \%)$ & \\
\hline Adult/Children & $272 / 69$ & $237 / 62$ & $35 / 7$ & 0.088 \\
\hline Mean Age (range) (years) & $34.88(1-74)$ & $31.47(1-74)$ & $31.48(6-66)$ & \\
\hline Sex (male/female) & $202 / 139$ & $181 / 118$ & $21 / 21$ & 0.102 \\
\hline $\mathrm{CP}$ prehistory & 23 & 21 & 2 & 0.778 \\
\hline \multicolumn{5}{|l|}{ Presenting Symptoms } \\
\hline Endocrine disturbance & $213(62.5 \%)$ & 184 & 29 & 0.105 \\
\hline Visual impairment & $219(64.2 \%)$ & 188 & 31 & 0.084 \\
\hline Headache & $192(56.3 \%)$ & 168 & 24 & 0.830 \\
\hline Nausea and Vomiting & $52(15.2 \%)$ & 43 & 9 & 0.723 \\
\hline Diabetes Inspidus & $53(15.5 \%)$ & 42 & 9 & 0.505 \\
\hline Dizziness & $45(13.2 \%)$ & 40 & 5 & 0.454 \\
\hline Amenorrhea & 23 & 19 & 4 & 0.125 \\
\hline Growth Retardation & 17 & 13 & 4 & 0.150 \\
\hline Weakness of Limbs & 16 & 14 & 2 & 0.424 \\
\hline Hydrocephalus & 15 & 15 & 0 & 0.497 \\
\hline Memory Decline & 10 & 9 & 1 & 0.230 \\
\hline Weight Gain/Loss & 7 & 7 & 0 & 0.318 \\
\hline Sexual Behavior Disturbance & 6 & 6 & 0 & 0.836 \\
\hline Fever & 6 & 6 & 0 & 0.932 \\
\hline Psycho-Behavioral changes & 5 & 4 & 1 & 0.595 \\
\hline Gait Instability & 5 & 5 & 0 & 0.834 \\
\hline Tinnitus & 3 & 3 & 0 & 0.871 \\
\hline Seizure & 2 & 1 & 1 & 0.489 \\
\hline Accidental finding following TBI imaging & 2 & 2 & 0 & 0.902 \\
\hline \multicolumn{5}{|l|}{ Tumor features } \\
\hline Cystic & $129(37.8 \%)$ & 109 & 20 & 0.970 \\
\hline Solid & $88(23.8 \%)$ & 75 & 13 & 0.952 \\
\hline Mixed & $124(36.4 \%)$ & 115 & 9 & 0.926 \\
\hline Calcification & $139(40.8 \%)$ & 125 & 14 & 0.504 \\
\hline Suprasellar & $198(58.1 \%)$ & 189 & 9 & $<0.0001^{*}$ \\
\hline Intrasellar & $40(11.7 \%)$ & 10 & 30 & $<0.0001^{*}$ \\
\hline Intra-third ventricular & $103(30.2 \%)$ & 100 & 3 & 0.638 \\
\hline \multicolumn{5}{|l|}{ Surgical Treatment and Outcome } \\
\hline Extent of Resection (GTR/STR) & $247 / 94$ & $220 / 89$ & $27 / 15$ & 0.208 \\
\hline Postoperative outcome (good/poor) & $324 / 17$ & $284 / 14$ & $39 / 3$ & 0.822 \\
\hline
\end{tabular}




\begin{tabular}{|c|c|c|c|c|}
\hline Continued & & & & \\
\hline Complications & 26 & 21 & 5 & 0.266 \\
\hline Postoperative diabetes inspidus & 298 & 261 & 37 & $<0.0001^{*}$ \\
\hline Recurrence (\%) & $44(12.9)$ & $35(79.5)$ & $9(20.5)$ & 0.776 \\
\hline Reoperation for Recurrence & 36 & 31 & 7 & 0.126 \\
\hline & 33 (PTE) & 26 (PTE) & & \\
\hline Surgical approach for Recurrence & 2 (Tcall) & 2 (Tcall) & 7 (PTE) & \\
\hline & 1 (TS) & 1 (TS) & & \\
\hline Mean Time to recurrence (range) (months) & $28.36(3-84)$ & $30(3-84)$ & $20.22(3-60)$ & \\
\hline Mean Length of hospital stay (range) (days) & $21.87(8-129)$ & $22.46(8-129)$ & $17.69(9-33)$ & \\
\hline Follow-up Survival (death/alive) & $26 / 315^{\mathrm{a}}$ & $25 / 273$ & $1 / 42$ & 0.562 \\
\hline
\end{tabular}

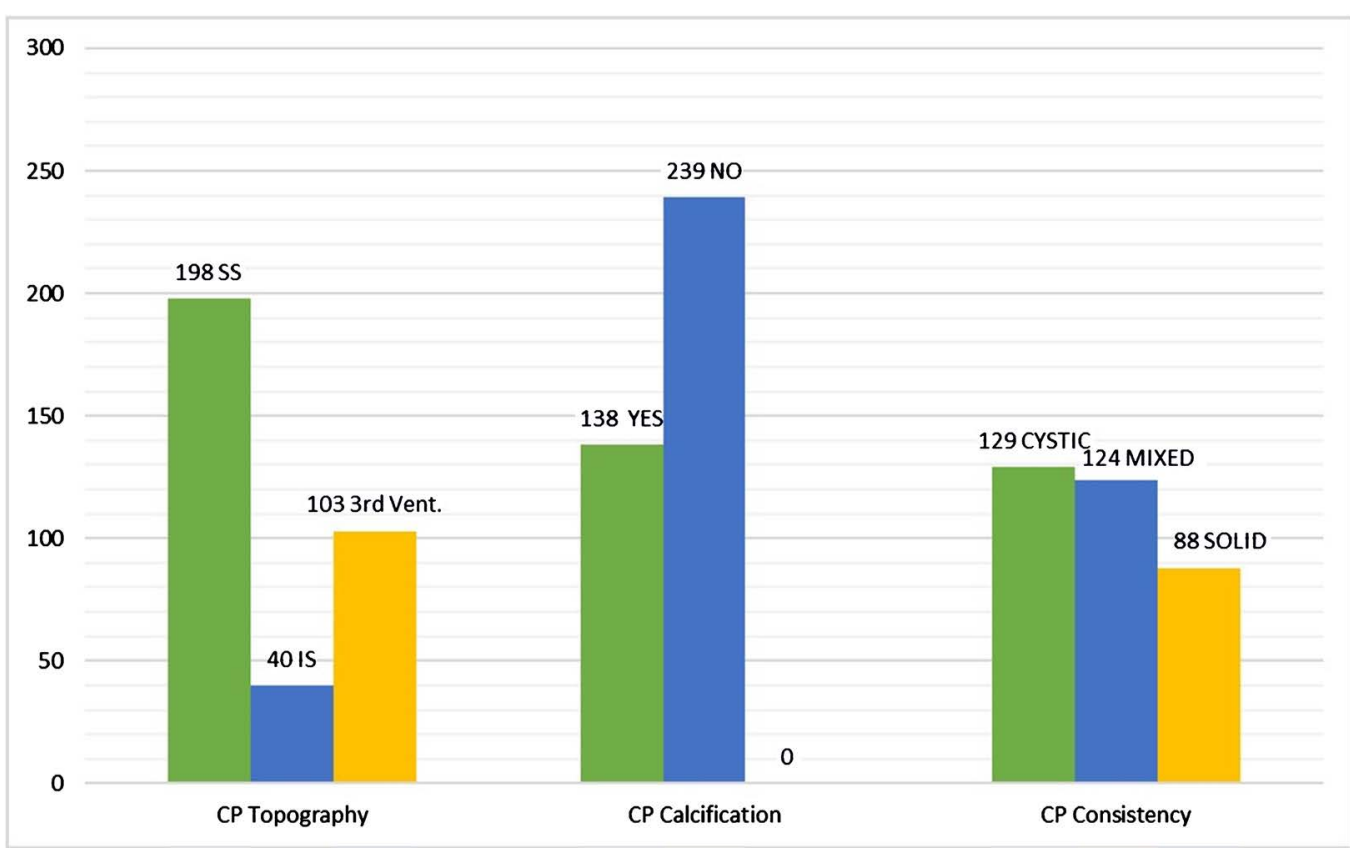

Figure 4. Showing summary of tumor features. SS—-suprasellar; IS—intrasellar; $3^{\text {rd }}$ Vent.-intra-third ventricular.

with all the three types of tumor consistency at the 0.01 level (2-tailed). Cystic and solid tumors had a linear negative correlation whereas mixed tumors had a positive correlation. Cystic CPs were encountered in $37.8 \%$ of the patients. The percentage of solid CPs was as $28.5 \%$ whereas the mixed consistency type constituted of $36.4 \%$. In children, the percentage occurrence of cystic CPs was similar to the mixed type (31.8\%). There was a significant correlation between headache on presentation and cystic tumors $(\mathrm{p}<0.0001)$ and mixed tumors $(\mathrm{p}=$ 0.037). Cystic tumors were more likely to present with hydrocephalus ( $\mathrm{p}=$ 0.004 ) with a positive correlation significant at 0.01 (2-tailored). The consistency of RCPs was similar to that of the primary CPs in the same patient.

Following the criteria of our new CP topography hypothesis defined in the material and methods section, there were 198 (58.1\%) Suprasellar 40 (11.7\%) 
intrasellar and 103 (30.2\%) intra-third ventricular CPs. To suppport our hypothesis, a correlation between various $\mathrm{CP}$ topography and presumed clinically relevant variables with results elaborated in following sections.

\subsection{Tumor Location}

Using our CP topography classification model as described in the section above, $58.1 \%$ of the patients had suprasellar CPs, 11.7\% intrasellar CPs while 103 (30.2\%) of the patients had intra-third ventricular CP (Figure 6). Among the pediatric patients, $37.7 \%$ had intra-third ventricular CP. Bivariate relationships between CP location and various clinical factors were assessed. Patients with suprasellar CP were more likely to present with headache $(\mathrm{p}=0.011)$; nausea and vomitus $(p=0.024)$; and amenorrhea $(p=0.033)$. There was a significant correlation between intrasellar $\mathrm{CP}$ location and preoperative diabetes insipidus $(\mathrm{p}=$ 0.026). Patients with intra-third ventricular $\mathrm{CP}$ were more likely to present with hydrocephalus $(\mathrm{p}=0.010)$; and nausea and vomiting $(\mathrm{p}=0.010)$. There was a significant positive correlation between intrasellar CPs and the use of transsphenoidal approach ( $p=0.002$ OR 0.153 ) Figure 4 illustrates intraoperative resection of a suprasellar CP.

\subsection{Surgical Results}

\subsubsection{Surgical Approach}

Fourth-two (12.3\%) surgeries were performed via trans-sphenoidal approach, whereas 299 (87.7\%) were performed via craniotomy. Table 1 shows the comparison in patient and tumor characteristics between the open transcranial group (OT) and transsphenoidal group (TS). OT was used more frequently in patients with suprasellar $(\mathrm{p}<0.0001)$ while TS was more used in the intrasellar CP location $(\mathrm{p}<0.0001)$ significant at 0.01 (2-tailored). There was an increased risk of postoperative DI in the OT group $(\mathrm{p}<0.0001)$. Among the transcranial group, pterional approach $(75.1 \%)$ was performed more frequently than other approaches. Only one patient underwent suboccipital approach for a pineal region $\mathrm{CP}$ suspected to be a meningioma on preoperative imaging. Similarly, only one patient underwent combined transcallossal-trans-choroidal approach with pterional-transsylvian approach to achieve total resection of a third ventricular $\mathrm{CP}$ with extension into the suprasellar region. Figure 5 shows the extent of resection in comparison with different surgical approaches used.

\subsubsection{Extent of Tumor Resection}

In our cohort, gross total resection (GTR) was achieved in 247 patients (72.4\%) whereas subtotal resection was achieved in 94 patients (27.6\%) as shown in Figure 5. Table 2 shows a list of bivariate significant relationships between the most important clinical variables related to extent of resection. A significant association was seen between extent of resection and cystic CP consistency ( $<<0.034$; Odds Ratio $=0.573$; CI: $0.329-0.982)$, mixed consistency ( $\mathrm{p}<0.017$; Odds Ratio $=1.833$; CI: $1.096-3.066$ ). There was a significantly greater risk for subtotal 


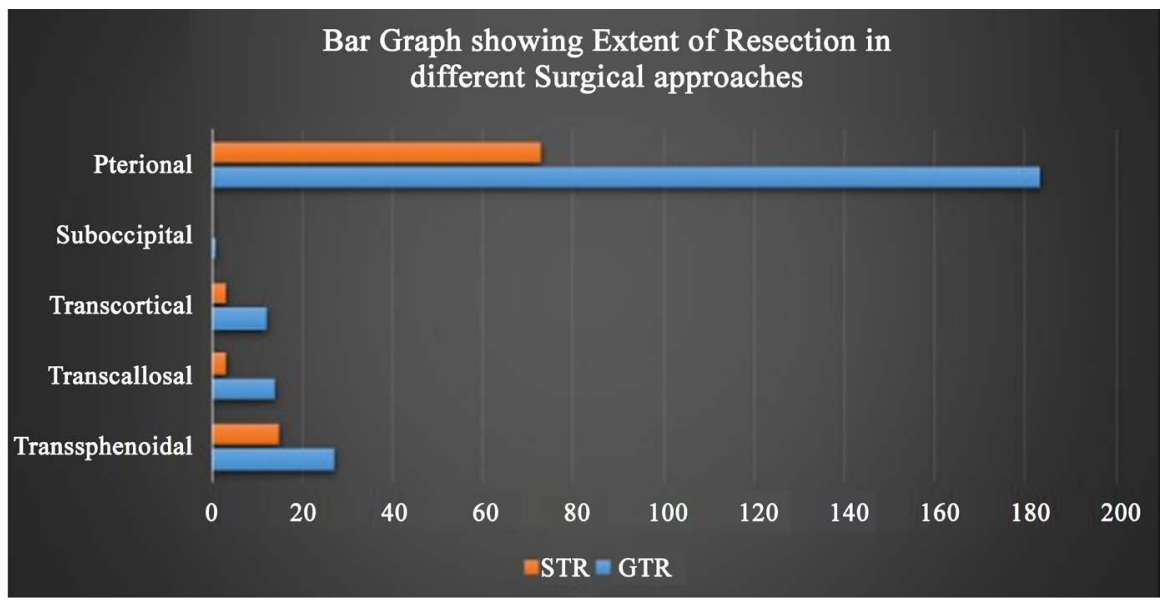

Figure 5. Bar graph showing number of cases extent of resection with different surgical approaches.

Table 2. Shows a list of bivariate significant relationships between the most important clinical variables related to extent of resection.

\begin{tabular}{|c|c|}
\hline Variable & $P$ value (GTR vs STR) \\
\hline Age & NS \\
\hline Sex & NS \\
\hline Prehistory & NS \\
\hline \multicolumn{2}{|l|}{ Major Presenting Symptoms: } \\
\hline Endocrine imbalance & NS \\
\hline Visual Impairment & NS \\
\hline Headache & NS \\
\hline Nausea and Vomiting & NS \\
\hline \multicolumn{2}{|l|}{ Tumor Features } \\
\hline Cystic & $0.034^{*}$ \\
\hline Mixed & $0.017^{*}$ \\
\hline Solid & NS \\
\hline Calcification & $0.0008^{*}$ \\
\hline \multicolumn{2}{|l|}{ Tumor Location } \\
\hline Suprasellar & $0.038^{*}$ \\
\hline Intrasellar & $0.009^{*}$ \\
\hline Intra-third ventricular & $0.025^{*}$ \\
\hline \multicolumn{2}{|l|}{ Surgical Approach } \\
\hline Open Craniotomy & 0.209 \\
\hline Pterional & NS \\
\hline Transcallosal-transchoroidal & NS \\
\hline Transcortical-transventricular & NS \\
\hline Trans-sphenoidal & 0.209 \\
\hline
\end{tabular}

NS $=$ non-significant; ${ }^{\star}$ significant at $\mathrm{p}=0.05$. 
resection in calcified CPs than noncalcified ( $<$ 0.0008; OR $=2.312$; CI: 1.388 3.872). Gross total resection was significantly achieved in suprasellar CPs ( $\mathrm{p}=$ 0.038; OR: 0.599; CI 0.361 - 0.995) and intrasellar ( $\mathrm{p}=0.009$, OR: 0.503; CI 0.299 - 0.845) but there was a significantly higher rate of subtotal resection in the intra-third ventricular CPs ( $\mathrm{p}<0.025$; OR 1.777; C.I 1.042 - 3.019). There was no significant correlation between choice of surgical approach and extent of resection.

\subsection{Variables Related to Postoperative Outcome}

\subsubsection{Hospital Stay and Survival}

The mean hospital stay was 21.9 days (SD 10.73) and range of 8 - 108 days. Table 3 shows the bivariate relationship between clinical factors and postoperative outcome. A good outcome was reported in $94.7 \%$ of the total series. In the poor

Table 3. Bivariate relationships between clinical factors and outcome.

\begin{tabular}{|c|c|}
\hline Variable & $P$ value \\
\hline Age & NS \\
\hline Sex & NS \\
\hline Prehistory & $0.099 \mathrm{NS}$ \\
\hline \multicolumn{2}{|l|}{ Major Presenting Symptoms: } \\
\hline Endocrine imbalance & NS \\
\hline Visual Impairment & NS \\
\hline Headache & NS \\
\hline Nausea and Vomiting & $0.05701 \mathrm{NS}$ \\
\hline \multicolumn{2}{|l|}{ Tumor Features } \\
\hline Cystic & NS \\
\hline Mixed & NS \\
\hline Solid & NS \\
\hline Calcification & NS \\
\hline \multicolumn{2}{|l|}{ Tumor Location } \\
\hline Suprasellar & NS \\
\hline Intrasellar & NS \\
\hline Intra-third ventricular & NS \\
\hline \multicolumn{2}{|l|}{ Surgical Approach } \\
\hline Open Craniotomy & NS \\
\hline Pterional & NS \\
\hline Transcallosal-transchoroidal & NS \\
\hline Transcortical-transventricular & NS \\
\hline Trans-sphenoidal & NS \\
\hline Extent of Resection & $0.788 \mathrm{NS}$ \\
\hline Postoperative DI & $0.082 \mathrm{NS}$ \\
\hline Long-term survival & $<0.0001^{*}$ \\
\hline
\end{tabular}

NS $=$ non-significant $;{ }^{*}$ significant at $\mathrm{p}=0.01$ (2-tailored). 
outcome group, the worst outcome (postoperative death) occurred in only five patients (1.5\%) whereas the other patients had poor prognosis following surgical treatment. None of our patients died during primary or secondary transsphenoidal surgery.

There was no significant correlation between outcome with the extent of tumor resection. In our series, we found no significant difference in the type of surgical approach. Although four of the five patients who suffered perioperative had intra-third ventricular $\mathrm{CP}$, we found no significant association between tumor location with postoperative outcome. There was a positive correlation between outcome and long term survival ( $\mathrm{p}<0.0001$ OR: 14.45).

\subsubsection{Neurological, Visual, and Endocrinological Outcomes}

No new visual impairments were reported postoperatively and all patients reported normal vision at discharge. Postoperative electrolyte disturbances and diabetes insipidus (87.4\%) were the most frequent finding usually coexisting with syndrome of inappropriate antidiuretic hormone secretion (SIADH). One child had severe hypothalamic dysfunction following GTR for a large suprasellar $\mathrm{CP}$ exhibited as postoperative memory loss and behavioral disorder and severe electrolyte imbalance which led to extensive hospital stay (122 days). The other complications are listed in Table 4.

\subsection{Tumor Recurrence}

Table 5 shows a summary for recurrence data in our cohort. The total recurrence rate of the cohort was $12.9 \%$ among forty-four patients. The overall mean time to recurrence was 28.36 months (range 3 - 84 months). Twenty-three patients admitted with prior history of CP surgery were not initially among the 44 patients with recurrence but were included in the study after undergoing surgical treatment at our institution. Among these, two patients had already been surgically

Table 4. Summary of Postoperative complications in the study cohort.

\begin{tabular}{ccc}
\hline Complication & Total Cases (\%) & Management \\
\hline $\begin{array}{c}\text { Electrolyte Imbalance and } \\
\text { Diabetes insipidus }\end{array}$ & $257(87.4)$ & Increased Fluid Intake and Desmopressin \\
Hydrocephalus & $9(3.7)$ & Ventro-peritoneal (VP) Shunting \\
Fever & 3 & Symptomatic treatment \\
Seizure & 1 & Prophylactic anti-epileptic medication \\
Cerebral spinal fluid leakage & 2 & Surgical duraplasty \\
Endocrine Disturbances & 11 & Appropriate Hormone Replacement \\
Hypothalamic damage & 4 & Conservative management \\
Wound infection & 1 & Surgical debridement \\
Postoperative intracranial & 4 & decompressive craniectomy and \\
hemorrhage & $5(1.5)$ & tracheostomy \\
Perioperative death & &
\end{tabular}


treated twice for $\mathrm{CP}$. As one of our primary objectives to determine the clinical factors related to recurrence, bivariate analysis was carried and results are shown in Table 6. Only prehistory of CP surgery was found to be the only factor to be

Table 5. Showing summary of recurrence data in our cohort of 341 patients.

\begin{tabular}{|c|c|c|c|}
\hline Event & No. of Cases (\%) & $\begin{array}{l}\text { Mean time to } \\
\text { recurrence (range) }\end{array}$ & Recurrence Management \\
\hline $\begin{array}{l}\text { Prehistory } \\
\text { Occurrence }\end{array}$ & $23(6.7)$ & $64.04(3-180)$ & $\begin{array}{l}23 \text { RCP Surgery (16 Pterional, } 4 \\
\text { Transsphenoidal, } 2 \text { Transcallosal) }\end{array}$ \\
\hline $1^{\text {st }}$ Recurrence & $44(12.9)$ & $28.36(3-84)$ months & $\begin{array}{c}37 \text { RCP Surgery (33 Pterional, } 2 \\
\text { Transcallosal; } 2 \text { Transsphenoidal) } \\
4 \text { Conservative; } 2 \text { GKS }\end{array}$ \\
\hline $2^{\text {nd }}$ Recurrence & $6(16.2)$ & $30(12-48)$ months & $\begin{array}{c}4 \text { RCP surgery (3 Pterional; } 1 \\
\text { Transphenoidal) } 2 \text { Conservative }\end{array}$ \\
\hline
\end{tabular}

Table 6. Analysis of the potential clinical risk factors related to CP recurrence.

\begin{tabular}{|c|c|}
\hline Variable & $P$ value \\
\hline Age & 0.216 \\
\hline Sex & 0.2599 \\
\hline Prehistory of Craniopharyngioma Surgery & $0.0001^{*}$ \\
\hline \multicolumn{2}{|l|}{ Major Presenting Symptoms: } \\
\hline Endocrine imbalance & 0.739 \\
\hline Visual Impairment & 0.130 \\
\hline Headache & 0.979 \\
\hline Nausea and Vomiting & 0.698 \\
\hline \multicolumn{2}{|l|}{ Tumor Features } \\
\hline Cystic & 0.621 \\
\hline Mixed & 0.615 \\
\hline Solid & 0.197 \\
\hline Calcification & 0.969 \\
\hline \multicolumn{2}{|l|}{ Tumor Location } \\
\hline Suprasellar & 0.627 \\
\hline Intrasellar & 0.621 \\
\hline Intra-third ventricular & 0.861 \\
\hline \multicolumn{2}{|l|}{ Surgical Approach } \\
\hline Open Craniotomy & 0.707 \\
\hline Pterional & 0.266 \\
\hline Transcallosal-transchoroidal & 0.534 \\
\hline Transcortical-transventricular & 0.703 \\
\hline Trans-sphenoidal & 0.303 \\
\hline Extent of Resection & 0.366 \\
\hline Follow-up survival & 0.271 \\
\hline
\end{tabular}

NS = non-significant; ${ }^{\star}$ significant at $\mathrm{p}=0.05$. 
significantly predictive of recurrence.

\subsection{Follow-Up Results}

Most patients $(n=229)$ were lost in the long-term follow-up by the recent follow-up call due to non-compliance or outdated contact information. 114 patients were available for follow-up analysis. The mean follow-up period was 64.5 months (SD 41.16; maximum 134 months). Our data in the long-term follow-up indicate that some patients still had existing neurological, ophthalmological, and endocrinological functional deficits without radiologic recurrence, mostly including visual disturbances (8); hypopituitarism (5) characterized by hypo-ACTH and permanent DI; and hypothalamic damage symptoms (4) including behavioral changes (4), memory decline (3) and obesity (4). Multivariate analysis of the factors related to long term survival revealed that Gender, Sex, Postop complications, postoperative diabetes insipidus were not significant at $\alpha=0.05$. However, poor outcome at discharge was significant at $\mathrm{p}<0.0001$ with a hazard ratio (favorable: unfavorable $)=\exp (2.298)=9.952$ deducing it as a high risk factor to long term survival. Recurrence is significantly related to long term survival with a Hazard risk of $(\exp (0.21598)=1.241$ indicating that recurrence is a risk factor.

Survival Rate. Survival analysis was of our cohort performed using Cox Regression Method. Twelve of patients by the recent long term follow-up had died within four years after surgery. The exact reasons for the death, whether surgery related or other comorbidities could not be established as relatives were not willing to discuss all details. A survival curve was plotted using Cox regression method (Figure 6).

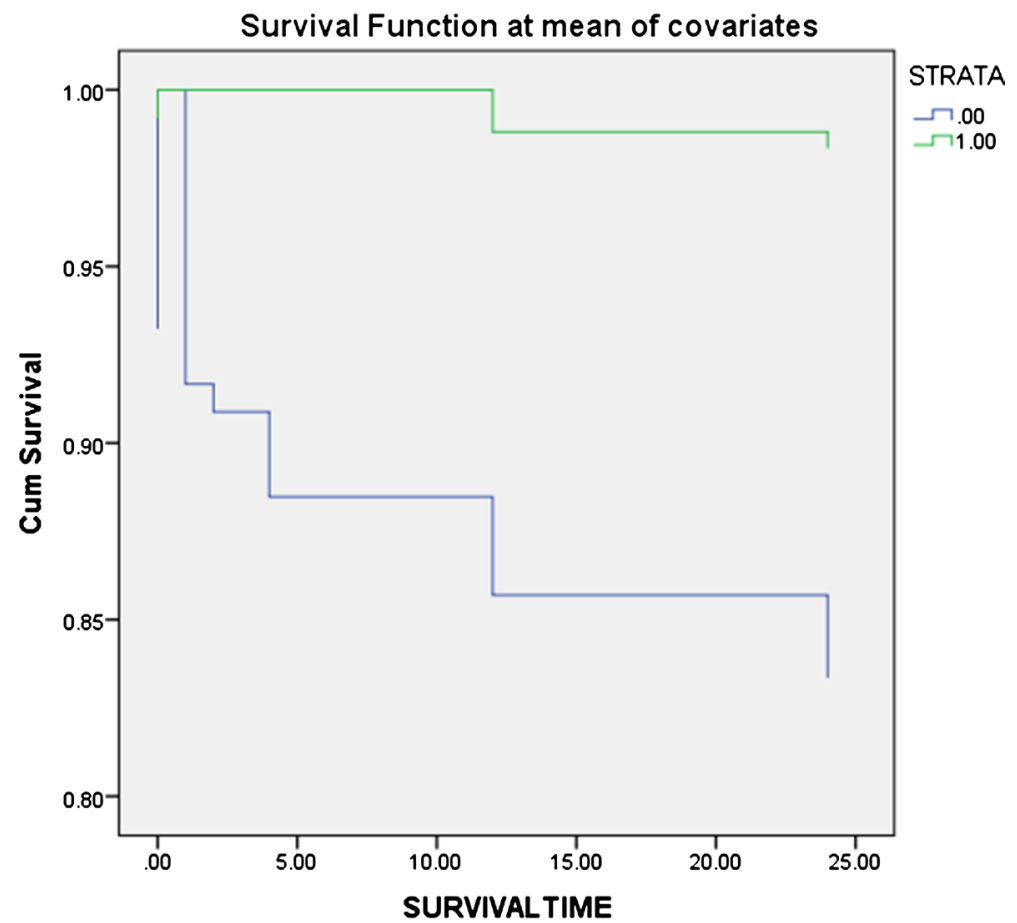

Figure 6. Survival curve at mean of covariates in the long-term follow up. 


\section{Discussion}

In the modern microsurgical era, the ultimate treatment standard for $\mathrm{CP}$ is still arguable. Whereas the possibility of prospective randomized trials to scientifically address this subjectis unlikely, findings from large retrospective surgical series like this one adds offers relevant to existing scientific literature, but also provides an analytical insight into the surgical management of CP in a decade at single institution.

\subsection{Patient Demographics and Presenting Symptoms}

There were more males (59.2\%) than females, more adults (79.8\%) than children in our series but this finding was not significant to any clinical factor. We found two peak incidences between $10-20$ years, and $40-50$ years, supporting the supposition of a binomial distribution of CP incidence deduced in several studies [6] [7] [10] [42]. In our cohort, most frequent major presenting symptom was visual impairment (64.2\%), followed by endocrine deficiency $62.5 \%$ and headache $56.3 \%$, similar to other studies [43]. In our series, the incidence of cystic, solid or mixed tumor consistency was not of statistical significance as well as the presence of calcification.

\subsection{Craniopharyngioma Topography Hypothesis}

In the light of no established consensus to date [8], several topographical classifications defining $\mathrm{CP}$ have been mentioned in literature with the most notable ones including Yasargil [12], Hoffman [9], Samii [44], Pascual [45], Kassam [46] and a recent anatomical-approach subclassification by Morisako [47], with the aim of aiding preoparative planning to achieve adequate resection. Our hypothetical classification system simplifies CP topography into three major categories namely suprasellar, intrasellar and intra-third ventricular and ectopic based on the major (widest diameter as seen both in any plane on MRI and intraoperative real-time location) $\mathrm{CP}$ mass anatomic occupation in relation to the sellar diaphragm. Although simplistic, this categorization nears description by Mastuo et al. [48] and Fatemi et al. [15]. We postulate that inasmuch as irregular extensions [49] [50] into proximate fissures between the three major locations described are of common occurence in CPs, they do not guarantee a specific taxonomy hence a defined category. This argument is consistent with our neuroradiologic reporting standard at our institution where intracranial mass lesions suspected to be $\mathrm{CP}$ are defined as one of suprasellar, intrasellar, intra-third ventricular, with or without extension, and has been used to designate $\mathrm{CP}$ location in all previous published studies of CP series at our institution [31] [32]. The ultimate goal of our classification system was to aid in choice of operative approach, along with other relevant clinical factors. Bivariate analysis results offered support to our hypothesis as most suprasellar tumors were significantly ( $\mathrm{p}$ $<0.0001)$ treated with open transcranial approaches whereas intrasellar CPs were significantly $(\mathrm{p}<0.0001)$ operated with transsphenoidal approach. 


\subsection{Selection of the Operative Approach}

In the past decade, lack of proper awareness of the topographic location due to $\mathrm{CP}$ variability in light of the existing diagnostic method was mentioned to influence poor outcome with associated surgical risks [45] [51]. An issue of specific interest in our study to assess the most appropriate surgical technique to achieve adequate degree of tumor removal for each patient, we performed a comparison between OT and TS approach with respect to postoperative outcome and other clinical factors. No superiority was seen in one choice over the other in relation to postoperative outcome. There was an increased risk of postoperative DI in the OT group ( $\mathrm{p}<0.0001$ ), similar to findings in other CP surgical series Shu Kai et al. [3] and Du et al. [52].

In our series, the open transcranial approach was significantly $(<0.0001)$ the most used choice forsuprasellar CPs particularly the pterional approach (85.6\%). We now ascertain that the pterional approach is superior to the others approaches in excising large suprasellar CPs, in line with findings from a systematic review of 3470 patients by Komotar comparing outcomes with different approaches [18]. This trans-sylvian fissure route offers a window of access for tumor removal through the opticocarotid triangles and the prechiasmatic space [10].

For intra-third ventricular CPs, the transcallosal-transchoroidal (5.1\%) approach was performed nearly as much as the transcortical-transventricular route (5.7\%) as the preferred approach. In parallel with our findings,several studies have demonstrated the preference of these routes for surgical removal of intra-third ventricular $\mathrm{CP}$ with or without extension to the suprasellar region [16] [49] [53]. However, Joao et al. argued that the transcallosal-transchoroidal approach offers a greater working space in the third ventricle than that afforded by the transchoroidal approach [54]. Contrary to tradition, in our series, three patients with intra-third ventricular $\mathrm{CP}$ were operated using the TS with good recovery but only one patient had recurrence after 12 months and was retreated by pterional approach, a feat similarly reported by Coppen and group [55].

Furthermore, the trasnsphenoidal route was used in $75 \%$ of the patients with intrasellar CPs, significantly more frequently $(\mathrm{p}=0.002$; $\mathrm{OR}=0.153)$ than the open transcranial approach. Our findings support our CP location hypothesis demonstrating that TS should be the approach of choice in purely intrasellar located CPs. Our results are supported by earlier CP studies at our institution exploring the effectiveness of TS approach for intrasellar or infradiaphragmatic CPs [2] [31] [32], as well as other studies in literature [10] [19] [55] [56]. This route was preferred in tumors which were purely intrasellar or in cystic suprasellar CPs with a large downward extension penetrating the sellar diaphragm into the sellar compartment. Fahlbusch et al. mentioned the challenge of having to split the displaced pituitary gland to achieve access to CP [10]. In disagreement, similar to recent report by Lei Ting et al. [2] our cohort chief surgeon, we equally did not encounter this challenge or find the need for resection of the pituitary 
stalk and suggest that conservative tumor removal can be achieved carefully by sharp excision of the CP capsule [57] from the normal pituitary tissue with the aid of neuronavigation and neuroendoscope to achieve maximal $\mathrm{CP}$ removal with preservation of the normal pituitary stalk. Figure 7 shows images of neuroendoscopic intraoperative inspection following microsurgical resection.

Cerebral spinal leak which required surgical duraplasty was only encountered in two patients who recovered fully while transient cases in the postoperative period were often treated conservatively or with lumbar puncture. Interestingly, while several authors have reiterated the advantageous use of endoscopic endonosal approach over traditional craniotomy and transsphenoidal microscopic approach in terms of greater tumor removal and outcome for CP treatment [18] [19] [46] [58] [59], we argue that general practice, it is difficult to compare open craniotomy and trans-sphenoid approaches because latter approach is choicely used for smaller and intrasellar tumors, while open craniotomy is primarily appropriated for large tumors with variable morphological features such as extension [49] or severe calcifications or evident vascular encasement seen on preoparative neuroimaging. In this present study, we would like to labor the point that the choice of surgical approach should be individualized according to the morphologic and topographic features manifested by the tumor on preoperative MRI/CT studies. Our philosophy is supported by other studies in which several
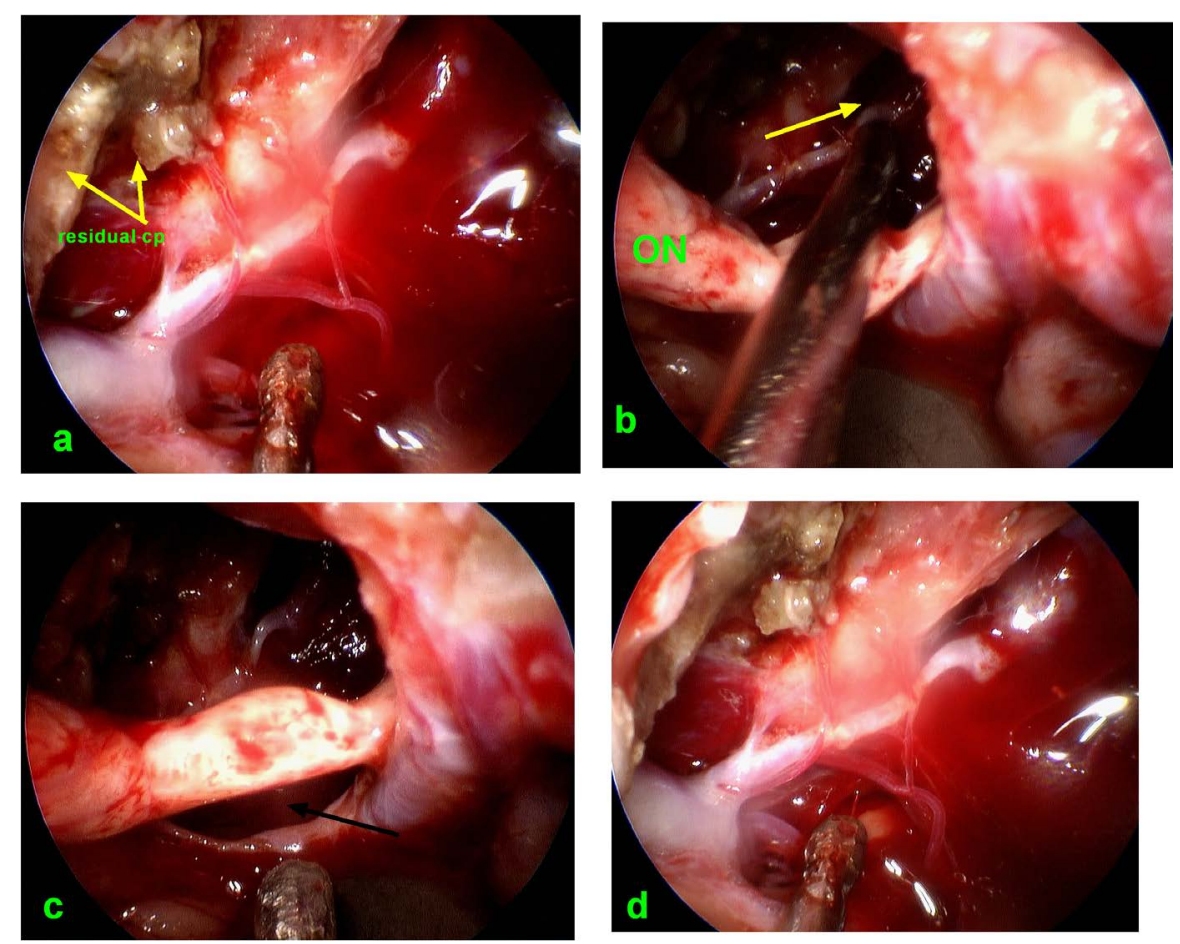

Figure 7. showing intra-endoscopic inspection following microscopic resection of an intrasellar CP. Notice the calcified tumor remnant (a) shown by the yellow arrows. In (b) careful inspection of prechiasmatic window, (c) black arrow shows the complete resection with careful preservation of the optic neural structures, (d) sumptuous preservation of the hypothalamic arteries. 
topography-specific approaches such as transpetrosal approach for suprasellar tumors with retrochiasmatic extension [60], endoscopic-assisted supraorbital approach [14] [15] [61]; and neuroendoscopic fenestration followed by RT for suprasellar cystic CPs [21] have been adopted with the aim of having the shortest route to tumor removal as well with acceptable morbidity.

\subsection{Extent of Tumor Resection and Postoperative Outcome}

From our literature review, it was observed that the accepted standard for the extent of tumor resection for CP and RCP continues to be contentious. Our principle of individualized approach was supported by Turel [62] and De Vile [63]. Nonetheless, most studies have advocated for gross total resection whenever possible [3] [12]. The variability of CP morphological features renders it surgically challenging to even the most skilled surgeons. [57] Calcifications, irregular extension into proximate anatomical space (Figure 8), tight adhesions to chiasm or intimate vascular structures, large size were the most encountered intraoperative challenges which led to the choice of subtotal resection, an emanation supported by numerous studies [10] [12] [16] [17]. Our data analyses revealed that cystic tumors offered a higher rate of total removal $(\mathrm{p}<0.017)$ whereas presence of calcification significantly favored subtotal resection $(\mathrm{p}<$ 0.0008). Others have adopted subtotal resection followed by radiotherapy [29] [64] [65] or gamma knife surgery [26] [27] to achieve acceptable tumor control
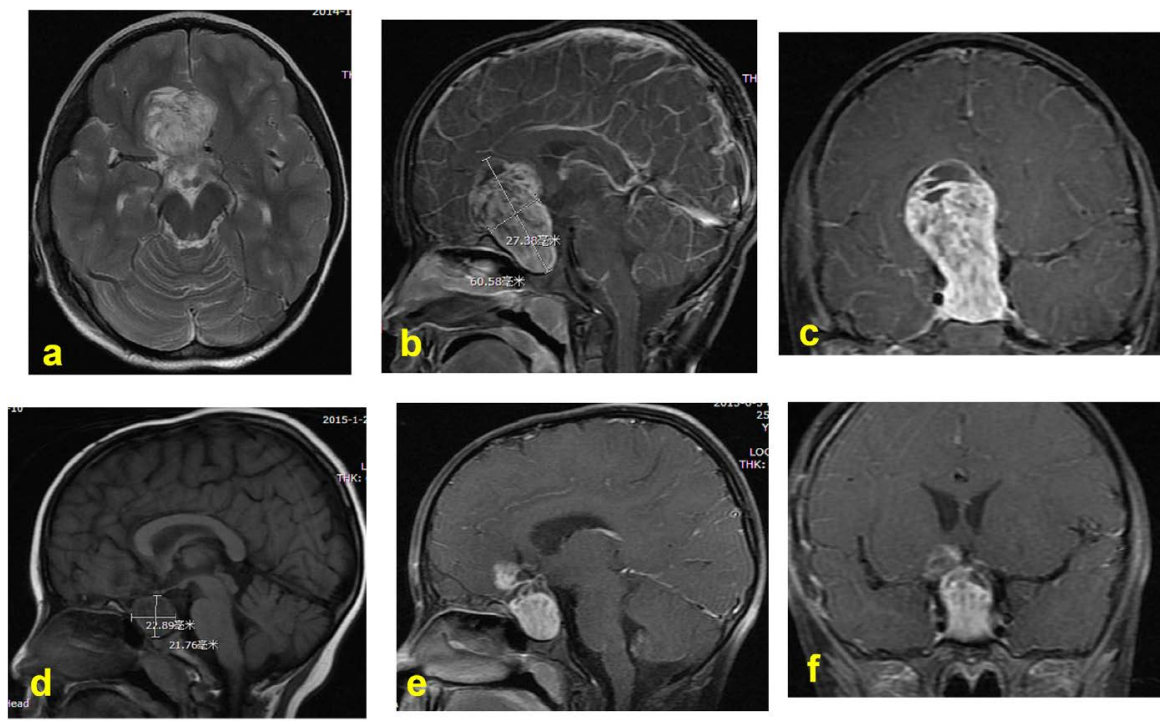

Figure 8. Showing an illustrative case of severe tumor extension into all the three primary tumor locations 3V-SS-IS. Preoperative MRI showing axial section (a) sagittal section (b) and coronal view of the CP. Due to the extensive large size, the operation was done in a two-stage method, first, the patient underwent transcranialpterional approach for subtotal resection of the suprasellar and intra-third ventricular portion of the tumor leaving an intentional residue in the intrasellar region. Notice the residual intrasellar solid portion observed 2 months after the first operation (d). At 7 months, the tumor size was symptomatically increased in size (e), (f) and subsequently underwent surgery via the same route. 
though with no uniform consensus. In a recent systematic review, Clark and associates found no difference in the one-year or five-year progression free rate between the patients treated with GTR alone and STR combined with radiation [30] Their results were consistent with Schoenfeld et al. findings [64]. In our cohort, although RT or GKS were not prescribed, however, three patients were treated by GKS at other institutions as reported in their clinical records in the postoperative follow-up period. There was no significant difference in extent of resection and long term survival, in agreement with findings in a study by Daubenbuchel and associates [23].

There was no difference in outcome between children and adults, contrary to findings by De Vile et al. who reported a significant association between poor out come and young age [63]. Similarly, we found no association between presenting symptoms and outcome. In contrast, other authors found a significant association between poor outcome and hydrocephalus [23] [66], visual disturbances [66] and presence of calcifications. There was no significant correlation between outcome with the surgical choice, but in disagreement, Pascaul [45] noted in surgical treatment of intra-third ventricular CPs, translaminar-terminalis approach was significantly associated a better postoperative outcome comparable to other approaches. In our series, there was no difference in postoperative outcome or long-term outcome between the GTR and STR. Our findings were similar to Duff et al. who concluded that proper assessment of surgical outcomes of $\mathrm{CP}$ patients should be ascertained not only the extent of resection but also the long-term outcome of patients [66], while Patel et al. found that GTR was associated with an increased quality of life $(\mathrm{p}=0.012)$ [67]. CP surgical treatment is however, not without surgical-associated postoperative complications [2] [68] [69] [70]. At $1.5 \%$ in our series, perioperative death the worst outcome was comparable to similar studies [53] [71] [72]. The major cause of death in the perioperative period was postoperative intracranial hemorrhage in four patients requiring craniectomy with subsequent malignant cerebral swelling to eventual death.

\subsection{Postoperative Electrolyte Disturbances and Endocrinilogical Deficits}

Microsurgical treatment of $\mathrm{CP}$ is notoriously challenged with postoperative electrolyte disturbances [24] [73] characterized by hypernatremia in the early postoperative period followed by hyponatremia in postop 4 - 6 days, usually coexisting with onset central diabetis insipidus, caused by intraoperative trauma to the hypothalus regions, pituitary infidibulum and posterior pituitary due to surgical manouvers. Endocrological disturbances [68] [69] may ensue along with electrolyte disturbances but this was not a common finding in our cohort. In our center, postoperative management of CP patients involves daily morning and evening routine check up of electrolytes panel and endocrinological panel every two days until discharge. Onset electrolyte disturbances and DI were treated 
with adequate hydrationand appropriate use of desmopressin [24]. Hydrocephalus [23] was reported in nine patients (2.6\%). In these patients, despite preoperative presentation with hydrocephalus with external ventricular drainage performed to offer symptomatic relief, VP shunt placement was eventually performed in 9 patients to offer definitve treatmentin the following months.

\subsection{Tumor Recurrence}

Tumor recurrence is a major conundrum to $\mathrm{CP}$ treatment and has been reported in nearly all $\mathrm{CP}$ surgical series with recurrence rates ranging from $4 \%$ to as high as $62 \%$ in published literature [4] [5] [44] [63] [74]. Our series of 341 patients reported a $12.9 \%$ recurrence rate, comparable to similar large CP series, [12] [43] [72] with a mean tumor free period of 28.36 (range: 3 - 84) months and 30 (range 12 - 48) months in the 6 patients with a second recurrence after surgical retreatment of RCP. The predictors of recurrence and optimum treatment of RCP still remain controvertible [41]. The debate centers around the universally accepted predictors of recurrence whether clinical, histopathological or molecular factors, which to date, inconsistently vary in different scientific reports leading to no consensus. Of specific interest to our study to determine the clinical factors related to recurrence, we hypothesized that residual tumor following subtotal resection is a risk factor to recurrence. There was a positive correlation between a prehistory of CP surgery and CP recurrence $(\mathrm{p}<0.0001)$ significant at 0.01 (2-tailored), indicating that in patients who recurrence occurred, even with surgical management there is a higher chance of tertiary recurrence. One patient in our cohort underwent a total of four CP surgeries to achieve total resection. In this patient, the primary surgery was undertaken 8 years before the second surgery, followed with recurrence and surgery two years after, but recurred again after one year with subsequent surgery. We found no significant relation between recurrence and age, sex or presenting symptoms, consistent with published studies [43] [66] [71] [75] [76] [77] but also contrary to several authors who identified age [63] [78] [79], male sex [41] [80], hydrocephalus [63], as clinical indicators of recurrence. Based on clinical experience, we predicted that cystic tumors of suprasellar location were possibly linked to a high likelihood of recurrence. This prediction was based on the high incidence of suprasellar (58.1\%) and cystic CPs (74.2\%) requiring variable surgical approaches at our institution. Although cystic tumors favored GTR $(\mathrm{p}<0.0001)$, bivariate analysis revealed no significant correlation between $\mathrm{CP}$ location, $\mathrm{CP}$ consistency, the choice of approach with the risk of recurrence. These findings were consistent with other studies in literature [63] [80] [81], although some authors have disclosed contrasting results [63] [78] [82]. Additionally, Komotar et al. mentioned the presence of intrasellar tumor residual as a major risk factor of reccurence [18]. A review of the literature (Table 7) revealed that a proportionate number of studies reported residual tumor to be a significant predictor of recurrence [9] [10] [11] [18] [43] [64] [75] [82] [83]. Interestingly, in our series, inasmuch as 
Table 7. Showing comparative results of large $(n>100)$ craniopharyngioma retrospective series.

\begin{tabular}{|c|c|c|c|c|c|c|c|}
\hline Zuccaro, 2005 [77] & $153 \mathrm{Ch}$ & 0 & - & $51 \%$ & 37 & & Residual CP \\
\hline Karavitaki et al., 2005 [50] & $12142 \mathrm{Ch}+79 \mathrm{Ad}$ & - & - & - & 30 & & Residual CP Non-RT \\
\hline Gupta et al., 2006 [86] & $12132 \mathrm{Ch}+89 \mathrm{Ad}$ & $13 \%$ & $30 \%$ & 16 & & 9 & $\begin{array}{c}\text { Residual CP Size }>4 \mathrm{~cm} \\
\text { Consistency }\end{array}$ \\
\hline Shi et al., 2008 [76] & $30950 \mathrm{Ch}+259 \mathrm{Ad}$ & $14 \%$ & $75 \%$ & & 22 & 6 & Residual CP Size $>6 \mathrm{~cm}$ \\
\hline Mortini et al., 2011 [78] & $11234 \mathrm{Ch}+78 \mathrm{Ad}$ & \multicolumn{5}{|c|}{ Global recurrence rate: $24.5 \%$} & Residual CP Non-RTGender \\
\hline Schoenfeld et al., 2012 [70] & $12247 \mathrm{Ch}+75 \mathrm{Ad}$ & $25 \%$ & $64 \%$ & $27 \%$ & 12 & & Residual CP Non-RT \\
\hline Gautier et al., 2012 [84] & $17165 \mathrm{Ch}+106 \mathrm{Ad}$ & $20 \%$ & $64 \%$ & $27 \%$ & 12 & & Residual CP Hd, Gender \\
\hline Current Study ${ }^{\star}$ & $34169 \mathrm{Ch} 272 \mathrm{Ad}$ & $11.7 \%$ & $15.7 \%$ & -- & 30.7 & 23.8 & $\begin{array}{c}\text { Prehistory of CP surgery } \\
\text { RESIDUAL CP NOT FOUND } \\
\text { SIGNIFICANT }\end{array}$ \\
\hline
\end{tabular}

the recurrence rate in the GTR group was $11.7 \%$ whereas $15.7 \%$ in the STR group, this result was not statistically significant. This is not surprising because numerous studies have reported recurrence even after GTR [74] [77] [84]. Our findings of non-significance of residual tumor due to STR with recurrence are in line with previous reports [71] [73] [85] [86]. It must be mentioned that compared to these studies, our large cohort of 341 patients may lend powering support to our findings. However, GTR offered a longer mean recurrence free period (31 months) compared to STR (24 months) although this finding was not statistically significant. Nevertheless, our findings of 24 months in the STR group was convincingly longer than in comparison to other $\mathrm{CP}$ series demonstrating that our individual-based approach may offer an acceptable morbidity free period for a patient before recurrence occurs.

\subsection{Treatment of Recurrent Craniopharyngioma and Long-Term Survival}

There was no significant association between outcome at discharge and recurrence rate. $84 \%$ of the RCP patients were surgically retreated primarily with pterional approach with unremarkable results. Only 6 patients, of which four underwent surgery were reported for secondary recurrence in the follow-up period. In our series, no significant association between recurrence and long-term survival was observed. Our results near those of Elliot and colleagues who observed no significant differences in postoperative outcome between primary $\mathrm{CP}$ and RCP patients [87], but further mentioned STR, large tumor size $(>5 \mathrm{~cm})$ and hydrocephalus as predictors of poor long-term survival [87]. Patel et al. proposed that tumor recurrence due to residual tumor was negatively associated with the long-term quality of life [67]. Our results help illustrate that long-term tumor control can be achieved with surgical treatment with or without adjuvant radiotherapy, in agreement with several studies [2] [10].

Regrettably, the surgical treatment of $\mathrm{CP}$ is universally challenging with longterm morbidities reported in several studies [66] [67]. Similar to other investi- 
gators, the most encountered morbidities included visual disturbances [43], hypopituitarism, permanent diabetes insipidus [43], hydrocephalus [23], obesity [77] and hypothalamic dysfunction [4] [23] [81].

In summary, the clinical predictors and optimal treatment of RCP continue to be debatable. While most studies analyzed small CP cohorts undergoing diversified therapeutic options, we argue that this factor obviate the relevance of the results. Nevertheless, the findings of our large cohort have reinstated that recurrence $\mathrm{CP}$ can be treated surgically in parallel with the treatment principles as for primary $\mathrm{CP}$ with the aim of performing adequate tumor resection to achieve definitive acceptable long-term outcomes without undergoing the risks associated with radiotherapy or chemotherapy [10].

\subsection{Potential Limitations}

Our study however, was not without limitations. First, the restrospective nature of our study is comparable to prospective studies in terms of implicit bias. Whether tumor size or shape, adhesions histological subtype, molecular analysis and radiologic findings were likely to impact the postoperative outcome or recurrence rate in our study was not elucidated since data on the clinical factors was inconsistently reported in some of the patients and therefore not included. Surgeries were performed by multiple surgeons which could lend a bias in the choice of surgical approach and treatment outcome due to disparities in personal preference. Our study could not include information on adjuvant radiation (AR) as it is not a routine treatment modality choice for $\mathrm{CP}$ at our center, as well as other less invasive adjuvant therapeutic modalities such as GKS, brachytherapy, mentioned in modern era management of $\mathrm{CP}$ with reported acceptable tumor control. Finally, there was incomplete long-term follow-up data due to outdated contact details. Future research protocols can look into these areas.

\section{Conclusion}

Based on our findings, we have shown that both gross total resection and selective subtotal resection offer a good postoperative outcome and long-term tumor control. Transcranial surgery was significantly more used in tumors of suprasellar location whereas transsphenoidal surgery was shown to be the preferred choice for intrasellar tumors. Residual tumor following subtotal resection was not found to be risk factor for recurrence. Only prehistory of craniopharyngioma surgery was found to be significant risk factor of craniopharyngioma recurrence. Due to tumor variability in patient to patient, we emphasize an individualized selective approach for the optimal choice of approach and degree of resection to achieve acceptable morbidity and long term tumor control.

\section{Acknowledgements}

I would first like to thank my thesis advisor Professor Dr. Med. Lei Ting MD $\mathrm{PhD}$, Chief of Neurosurgery Department at Tongji Hospital of Tongji Medical 
College of Huazhong University of Science and Technology. Prof. Lei has been a supervisor, a role model and mentor throughout conducting this study. I would also like to thank my teachers and colleagues who were supportive throughout this project and involved in the validation survey for this research project at different levels: Wan Xueyuan for the statistical analysis, Zhang Xiaoqing, Lei Yuan for data collection, Wu Likun, Juan Chen, and Liu Sheng Wenfor material support and critical reviews; all Professors and resident doctors, nurses and classmates of the neurosurgical department of Tongji Hospital for being hospitable and providing an amicable learning environment. Without their passionate participation and input, the validation survey could not have been successfully conducted. I would also like to acknowledge Prof. Shu Kai, Asst. Prof. Zhang Huaqiu and Asst. Prof. Zeng Liang, doctors at Department of Neurosurgery of Tongi Hospital, as internal reviewers of this manuscript. Lastly, great thanks to my wife Faith and my lovely son Minguel who have been closely supportive from a distance.

\section{Conflicts of Interest}

The authors declare no conflicts of interest regarding the publication of this paper.

\section{References}

[1] Louis, D.N., et al. (2007) The 2007 WHO Classification of Tumours of the Central Nervous System. Acta Neuropathologica, 114, 97-109. https://doi.org/10.1007/s00401-007-0243-4

[2] Lei, T., et al. (2016) Transsphenoidal Microsurgical Treatment of Infradiaphragmatic Craniopharyngioma. Chinese-German Journal of Clinical Oncology, 2, 197202.

[3] Li, L., Shu, G.Y. and Han, L. (2008) Microsurgical Treatment of Craniopharyngioma. Central China Medical Journal, 32, 93-95.

[4] Hoffmann, A., et al. (2014) Childhood Craniopharyngioma-Changes of Treatment Strategies in the Trials KRANIOPHARYNGEOM 2000/2007. Klinische Pädiatrie, 226, 161-168. https://doi.org/10.1055/s-0034-1368785

[5] Muller, H.L. (2014) Craniopharyngioma. Endocrine Reviews, 35, 513-543. https://doi.org/10.1210/er.2013-1115

[6] Nielsen, E.H., et al. (2011) Incidence of Craniopharyngioma in Denmark ( $\mathrm{n}=189)$ and Estimated World Incidence of Craniopharyngioma in Children and Adults. Journal of Neuro-Oncology, 104, 755-763. https://doi.org/10.1007/s11060-011-0540-6

[7] Bunin, G.R., et al. (1997) The Descriptive Epidemiology of Craniopharyngioma. Neurosurgical Focus, 3, e1. https://doi.org/10.3171/foc.1997.3.6.4

[8] Lubuulwa, J. and Lei, T. (2016) Pathological and Topographical Classification of Craniopharyngiomas: A Literature Review. Journal of Neurological Surgery Reports, 77, e121-e127. https://doi.org/10.1055/s-0036-1588060

[9] Hoffman, H.J. (1994) Surgical Management of Craniopharyngioma. Pediatric Neurosurgery, 21, 44-49. https://doi.org/10.1159/000120861

[10] Fahlbusch, R., Honegger, J., Paulus, W., Huk, W. and Buchfelder, M. (1999) Surgic- 
al Treatment of Craniopharyngiomas: Experience with 168 Patients. Journal of Neurosurgery, 90, 237-250. https://doi.org/10.3171/jns.1999.90.2.0237

[11] Crotty, T.B., et al. (1995) Papillary Craniopharyngioma: A Clinicopathological Study of 48 Cases. Journal of Neurosurgery, 83, 206-214.

https://doi.org/10.3171/jns.1995.83.2.0206

[12] Yasargil, M.G., et al. (1990) Total Removal of Craniopharyngiomas. Approaches and Long-Term Results in 144 Patients. Journal of Neurosurgery, 73, 3-11. https://doi.org/10.3171/jns.1990.73.1.0003

[13] Tawk, R.G., et al. (2014) Transciliary Supraorbital Approach (Eyebrow Approach) for Resection of Retrochiasmatic Craniopharyngiomas: An Alternative Approach, Case Series, and Literature Review. Journal of Neurological Surgery Part A: Central European Neurosurgery, 75, 354-364. https://doi.org/10.1055/s-0033-1358609

[14] Dlouhy, B.J., Chae, M.P. and Teo, C. (2015) The Supraorbital Eyebrow Approach in Children: Clinical Outcomes, Cosmetic Results, and Complications. Journal of Neurosurgery: Pediatrics, 15, 12-19. https://doi.org/10.3171/2014.10.PEDS1430

[15] Fatemi, N., et al. (2009) Endonasal versus Supraorbital Keyhole Removal of Craniopharyngiomas and Tuberculum Sellae Meningiomas. Neurosurgery, 64, 269-284. https://doi.org/10.1227/01.NEU.0000327857.22221.53

[16] Chamoun, R. and Couldwell, W.T. (2013) Transcortical-Transforaminal Microscopic Approach for Purely Intraventricular Craniopharyngioma. Neurosurgical Focus, 34, Video 4. https://doi.org/10.3171/2013.V1.FOCUS12347

[17] Yano, S., et al. (2015) A Flexible Endoscope-Assisted Interhemispheric Transcallosal Approach through the Contralateral Ventricle for the Removal of a Third Ventricle Craniopharyngioma: A Technical Report. Surgical Neurology International, 6, S113S116. https://doi.org/10.4103/2152-7806.153653

[18] Komotar, R.J., Starke, R.M., Raper, D.M.S., An, V.K. and Schwartz, T.H. (2012) Endoscopic Endonasal Compared with Microscopic Transsphenoidal and Open Transcranial Resection of Craniopharyngiomas. World Neurosurgery, 77, 329-341. https://doi.org/10.1016/j.wneu.2011.07.011

[19] Cavallo, L.M., et al. (2009) Extended Endoscopic Endonasal Transsphenoidal Approach for Residual or Recurrent Craniopharyngiomas. Journal of Neurosurgery, 111, 578-589. https://doi.org/10.3171/2009.2.JNS081026

[20] Shukla, D. (2015) Transcortical Transventricular Endoscopic Approach and Ommaya Reservoir Placement for Cystic Craniopharyngioma. Pediatric Neurosurgery, 50, 291-294. https://doi.org/10.1159/000433605

[21] Takano, S., et al. (2015) Neuroendoscopy Followed by Radiotherapy in Cystic Craniopharyngiomas-A Long-Term Follow Up. World Neurosurgery, 84, 1305-1315.e2. https://doi.org/10.1016/j.wneu.2015.06.022

[22] Yamini, B. and Narayanan, M. (2006) Craniopharyngiomas: An Update. Expert Review of Anticancer Therapy, 6, S85-S92. https://doi.org/10.1586/14737140.6.9s.S85

[23] Daubenbuchel, A.M., et al. (2015) Hydrocephalus and Hypothalamic Involvement in Pediatric Patients with Craniopharyngioma or Cysts of Rathke's Pouch: Impact on Long-Term Prognosis. European Journal of Endocrinology, 172, 561-569. https://doi.org/10.1530/EJE-14-1029

[24] Arima, H., et al. (2016) Central Diabetes Insipidus. Nagoya Journal of Medical Science, 78, 349-358.

[25] Smith, T.R., et al. (2016) Physiological Growth Hormone Replacement and Rate of Recurrence of Craniopharyngioma: The Genentech National Cooperative Growth 
Study. Journal of Neurosurgery. Pediatrics, 18, 408-412. https://doi.org/10.3171/2016.4.PEDS16112

[26] Amendola, B.E., Wolf, A., Coy, S.R. and Amendola, M.A. (2003) Role of Radiosurgery in Craniopharyngiomas: A Preliminary Report. Medical and Pediatric Oncology, 41, 123-127. https://doi.org/10.1002/mpo.10364

[27] Lee, C.C., et al. (2014) Gamma Knife Surgery for Craniopharyngioma: Report on a 20-Year Experience. Journal of Neurosurgery, 121, 167-178. https://doi.org/10.3171/2014.8.GKS141411

[28] Ito, M., Jamshidi, J. and Yamanaka, K. (2001) Does Craniopharyngioma Metastasize? Case Report and Review of the Literature. Neurosurgery, 48, 933-935. https://doi.org/10.1227/00006123-200104000-00050

[29] Wara, W.M., Sneed, P.K. and Larson, D.A. (1994) The Role of Radiation Therapy in the Treatment of Craniopharyngioma. Pediatric Neurosurgery, 21, 98-100. https://doi.org/10.1159/000120869

[30] Clark, A.J., et al. (2013) A Systematic Review of the Results of Surgery and Radiotherapy on Tumor Control for Pediatric Craniopharyngioma. Child s Nervous System, 29, 231-238. https://doi.org/10.1007/s00381-012-1926-2

[31] Lei, T., et al. (2008) Transsphenoidal Route for Microsurgical Resection of Craniopharyngioma. Central China Medical Journal, 24, 493-495.

[32] Lei, T., et al. (2013) Transsphenoidal Route for Microsurgical Resection of Infradiaphragm Craniopharyngioma. Chinese Journal of Clinical Neurosurgery, No. 11, 657-660.

[33] Renn, W.H. and Rhoton Jr., A.L. (1975) Microsurgical Anatomy of the Sellar Region. Journal of Neurosurgery, 43, 288-298. https://doi.org/10.3171/jns.1975.43.3.0288

[34] Yamamoto, I., Rhoton Jr., A.L. and Peace, D.A. (1981) Microsurgery of the Third Ventricle: Part I. Microsurgical Anatomy. Neurosurgery, 8, 334-356. https://doi.org/10.1227/00006123-198103000-00006

[35] Bikmaz, K., et al. (2009) Ectopic Recurrence of Craniopharyngiomas: Case Report. Neurosurgery, 64, E382-E383. https://doi.org/10.1227/01.NEU.0000337078.60998.98

[36] Nourbakhsh, A., et al. (2010) Extracranial Infrasellar Ectopic Craniopharyngioma: A Case Report and Review of the Literature. Skull Base, 20, 475-480. https://doi.org/10.1055/s-0030-1261269

[37] Schmalisch, K., et al. (2010) Postoperative Intracranial Seeding of Craniopharyngiomas-Report of Three Cases and Review of the Literature. Acta Neurochirurgica (Wien), 152, 313-319. https://doi.org/10.1007/s00701-009-0538-4

[38] Goncalves, C.B., et al. (2014) Subgaleal Recurrence of Craniopharyngioma of Rapid Growing Pattern. Pituitary, 17, 214-219. https://doi.org/10.1007/s11102-013-0490-4

[39] Ortega-Porcayo, L.A., et al. (2015) Primary Ectopic Frontotemporal Craniopharyngioma. International Journal of Surgery Case Reports, 9, 57-60. https://doi.org/10.1016/j.ijscr.2014.12.038

[40] Clark, S.W., Kenning, T.J. and Evans, J.J. (2015) Recurrent Ectopic Craniopharyngioma in the Sylvian Fissure Thirty Years after Resection through a Pterional Approach: A Case Report and Review of the Literature. Nagoya Journal of Medical Science, 77, 297-306.

[41] Minamida, Y., et al. (2005) Surgical Management of the Recurrence and Regrowth of Craniopharyngiomas. Journal of Neurosurgery, 103, 224-232. 
https://doi.org/10.3171/jns.2005.103.2.0224

[42] Sorva, R. and Heiskanen, O. (1986) Craniopharyngioma in Finland. A Study of 123 Cases. Acta Neurochirurgica (Wien), 81, 85-89. https://doi.org/10.1007/BF01401226

[43] Karavitaki, N., et al. (2005) Craniopharyngiomas in Children and Adults: Systematic Analysis of 121 Cases with Long-Term Follow-Up. Clinical Endocrinology $(O x f)$, 62, 397-409. https://doi.org/10.1111/j.1365-2265.2005.02231.x

[44] Samii, M. and Tatagiba, M. (1997) Surgical Management of Craniopharyngiomas: A Review. Neurologia Medico-Chirurgica (Tokyo), 37, 141-149. https://doi.org/10.2176/nmc.37.141

[45] Pascual, J.M., et al. (2004) Intraventricular Craniopharyngiomas: Topographical Classification and Surgical Approach Selection Based on an Extensive Overview. Acta Neurochirurgica (Wien), 146, 785-802. https://doi.org/10.1007/s00701-004-0295-3

[46] Kassam, A.B., et al. (2008) Expanded Endonasal Approach, a Fully Endoscopic Transnasal Approach for the Resection of Midline Suprasellar Craniopharyngiomas: A New Classification Based on the Infundibulum. Journal of Neurosurgery, 108, 715-728. https://doi.org/10.3171/JNS/2008/108/4/0715

[47] Morisako, H., et al. (2016) Aggressive Surgery Based on an Anatomical Subclassification of Craniopharyngiomas. Neurosurgical Focus, 41, E10. https://doi.org/10.3171/2016.9.FOCUS16211

[48] Matsuo, T., et al. (2014) Indication and Limitations of Endoscopic Extended Transsphenoidal Surgery for Craniopharyngioma. Neurologia Medico-Chirurgica ( Tokyo), 54, 974-982. https://doi.org/10.2176/nmc.oa.2014-0038

[49] Gerganov, V., et al. (2014) Microsurgical Resection of Extensive Craniopharyngiomas Using a Frontolateral Approach: Operative Technique and Outcome. Journal of Neurosurgery, 120, 559-570. https://doi.org/10.3171/2013.9.JNS122133

[50] Link, M.J., Driscoll, C.L. and Giannini, C. (2002) Isolated, Giant Cerebellopontine Angle Craniopharyngioma in a Patient with Gardner Syndrome: Case Report. Neurosurgery, 51, 221-225. https://doi.org/10.1097/00006123-200207000-00033

[51] Pascual, J.M., et al. (2014) Development of Intracranial Approaches for Craniopharyngiomas: An Analysis of the First 160 Historical Procedures. Neurosurgical Focus, 36, E13. https://doi.org/10.3171/2014.2.FOCUS13567

[52] Du, C., et al. (2016) Microsurgical Management of Craniopharyngiomas via a Unilateral Subfrontal Approach: A Retrospective Study of 177 Continuous Cases. World Neurosurgery, 90, 454-468. https://doi.org/10.1016/j.wneu.2016.03.002

[53] Shi, X., Zhang, Y. and Wu, B. (2003) Surgical Experience of 179 Cases with Craniopharyngiomas. Journal of Peking University, 35, 515-520.

[54] Vitorino Araujo, J.L., et al. (2016) Comparative Anatomical Analysis of the Transcallosal-Transchoroidal and Transcallosal-Transforniceal-Transchoroidal Approaches to the Third Ventricle. Journal of Neurosurgery, 127, 1-10. https://doi.org/10.3171/2016.8.JNS16403.test

[55] Coppens, J.R. and Couldwell, W.T. (2010) Staged Use of the Transsphenoidal Approach to Resect Superior Third Ventricular Craniopharyngiomas. Minimally Invasive Neurosurgery, 53, 40-43. https://doi.org/10.1055/s-0029-1246160

[56] Cote, D.J., Wiemann, R., Smith, T.R., Dunn, I.F., Al-Mefty, O. and Laws, E.R. (2015) The Expanding Spectrum of Disease Treated by the Transnasal, Transsphenoidal Microscopic and Endoscopic Anterior Skull Base Approach: A Single-Center Experience 2008-2015. World Neurosurgery, 82, S152-S154. 
https://doi.org/10.1016/j.wneu.2015.05.019

[57] Laws Jr., E.R. (2010) Surgical Outcome in 90 Patients with Craniopharyngiomas: An Evaluation of the Transsphenoidal Approach. World Neurosurgery, 74, 254-255. https://doi.org/10.1016/j.wneu.2010.07.033

[58] Lobo, B., et al. (2015) The Expanding Role of the Endonasal Endoscopic Approach in Pituitary and Skull Base Surgery: A 2014 Perspective. Surgical Neurology International, 6, 82. https://doi.org/10.4103/2152-7806.157442

[59] Yadav, Y.R., et al. (2015) Endoscopic Endonasal Trans-Sphenoid Management of Craniopharyngiomas. Asian Journal of Neurosurgery, 10, 10-16.

https://doi.org/10.4103/1793-5482.151502

[60] Kunihiro, N., Goto, T., Ishibashi, K. and Ohata, K. (2014) Surgical Outcomes of the Minimum Anterior and Posterior Combined Transpetrosal Approach for Resection of Retrochiasmatic Craniopharyngiomas with Complicated Conditions. Journal of Neurosurgery, 120, 1-11. https://doi.org/10.3171/2013.10.JNS13673

[61] Wilson, D.A., et al. (2014) The Supraorbital Endoscopic Approach for Tumors. World Neurosurgery, 82, S72-S80. https://doi.org/10.1016/j.wneu.2014.07.029

[62] Turel, M.K., et al. (2016) Management and Outcome of Recurrent Adult Craniopharyngiomas: An Analysis of 42 Cases with Long-Term Follow-Up. Neurosurgical Focus, 41, E11. https://doi.org/10.3171/2016.9.FOCUS16315

[63] De Vile, C.J., et al. (1996) Management of Childhood Craniopharyngioma: Can the Morbidity of Radical Surgery Be Predicted? Journal of Neurosurgery, 85, 73-81. https://doi.org/10.3171/jns.1996.85.1.0073

[64] Schoenfeld, A., et al. (2012) The Superiority of Conservative Resection and Adjuvant Radiation for Craniopharyngiomas. Journal of Neuro-Oncology, 108, 133-139. https://doi.org/10.1007/s11060-012-0806-7

[65] Davies, M.J., King, T.T., Metcalfe, K.A. and Monson, J.P. (1997) Intraventricular Craniopharyngioma: A Long-Term Follow-Up of Six Cases. British Journal of Neurosurgery, 11, 533-541. https://doi.org/10.1080/02688699745691

[66] Duff, J., et al. (2000) Long-Term Outcomes for Surgically Resected Craniopharyngiomas. Neurosurgery, 46, 291-302.

https://doi.org/10.1097/00006123-200002000-00007

[67] Patel, K.S., et al. (2015) Long-Term Quality of Life after Endonasal Endoscopic Resection of Adult Craniopharyngiomas. Journal of Neurosurgery, 123, 1-10.

[68] Campbell, P.G., et al. (2010) Endocrinological and Ophthalmological Consequences of an Initial Endonasal Endoscopic Approach for Resection of Craniopharyngiomas. Neurosurgical Focus, 28, E8. https://doi.org/10.3171/2010.1.FOCUS09292

[69] Yamada, S., et al. (2010) Surgical Outcome in 90 Patients with Craniopharyngioma: An Evaluation of Transsphenoidal Surgery. World Neurosurgery, 74, 320-330. https://doi.org/10.1016/j.wneu.2010.06.014

[70] Bianco Ade, M., et al. (2006) Cortical Seeding of a Craniopharyngioma after Craniotomy: Case Report. Surgical Neurology, 66, 437-440.

https://doi.org/10.1016/j.surneu.2005.12.027

[71] Bulow, B., et al. (1998) Postoperative Prognosis in Craniopharyngioma with Respect to Cardiovascular Mortality, Survival, and Tumor Recurrence. The Journal of Clinical Endocrinology and Metabolism, 83, 3897-3904. https://doi.org/10.1210/jc.83.11.3897

[72] Shi, X.E., et al. (2008) Craniopharyngioma: Surgical Experience of 309 Cases in China. Clinical Neurology and Neurosurgery, 110, 151-159. 
https://doi.org/10.1016/j.clineuro.2007.10.013

[73] Zuccaro, G. (2005) Radical Resection of Craniopharyngioma. Child s Nervous System, 21, 679-690. https://doi.org/10.1007/s00381-005-1201-x

[74] Mortini, P., et al. (2011) Neurosurgical Treatment of Craniopharyngioma in Adults and Children: Early and Long-Term Results in a Large Case Series. Journal of Neurosurgery, 114, 1350-1359. https://doi.org/10.3171/2010.11.JNS10670

[75] Tena-Suck, M.L., et al. (2006) Clinico-Pathological and Immunohistochemical Characteristics Associated to Recurrence/Regrowth of Craniopharyngiomas. Clinical Neurology and Neurosurgery, 108, 661-669. https://doi.org/10.1016/j.clineuro.2006.01.007

[76] Kim, S.K., et al. (2001) Radical Excision of Pediatric Craniopharyngioma: Recurrence Pattern and Prognostic Factors. Child s Nervous System, 17, 531-536. https://doi.org/10.1007/s003810100459

[77] Tomita, T. and Bowman, R.M. (2005) Craniopharyngiomas in Children: Surgical Experience at Children's Memorial Hospital. Child s Nervous System, 21, 729-746. https://doi.org/10.1007/s00381-005-1202-9

[78] Steno, J., Bízik, I., Šteňo, A. and Matejčík, V. (2014) Recurrent Craniopharyngiomas in Children and Adults: Long-Term Recurrence Rate and Management. Acta Neurochirurgica (Wien), 156, 113-122. https://doi.org/10.1007/s00701-013-1938-Z

[79] Agozzino, L., et al. (2006) Morphological and Ultrastructural Findings of Prognostic Impact in Craniopharyngiomas. Ultrastructural Pathology, 30, 143-150. https://doi.org/10.1080/01913120500408018

[80] Gautier, A., et al. (2012) Markers of Recurrence and Long-Term Morbidity in Craniopharyngioma: A Systematic Analysis of 171 Patients. The Journal of Clinical Endocrinology and Metabolism, 97, 1258-1267. https://doi.org/10.1210/jc.2011-2817

[81] Puget, S., et al. (2007) Pediatric Craniopharyngiomas: Classification and Treatment According to the Degree of Hypothalamic Involvement. Journal of Neurosurgery, 106, 3-12. https://doi.org/10.3171/ped.2007.106.1.3

[82] Gupta, D.K., et al. (2006) Recurrence in Craniopharyngiomas: Analysis of Clinical and Histological Features. Journal of Clinical Neuroscience, 13, 438-442. https://doi.org/10.1016/j.jocn.2005.05.013

[83] Losa, M., et al. (2004) Correlation between Clinical Characteristics and Proliferative Activity in Patients with Craniopharyngioma. Journal of Neurology, Neurosurgery \& Psychiatry, 75, 889-892. https://doi.org/10.1136/jnnp.2003.012781

[84] Liubinas, S.V., Munshey, A.S. and Kaye, A.H. (2011) Management of Recurrent Craniopharyngioma. Journal of Clinical Neuroscience, 18, 451-457. https://doi.org/10.1016/j.jocn.2010.10.004

[85] Fisher, P.G., et al. (1998) Outcomes and Failure Patterns in Childhood Craniopharyngiomas. Child s Nervous System, 14, 558-563. https://doi.org/10.1007/s003810050272

[86] Thompson, D., Phipps, K. and Hayward, R. (2005) Craniopharyngioma in Childhood: Our Evidence-Based Approach to Management. Child s Nervous System, 21, 660-668. https://doi.org/10.1007/s00381-005-1210-9

[87] Elliott, R.E., et al. (2010) Efficacy and Safety of Radical Resection of Primary and Recurrent Craniopharyngiomas in 86 Children. Journal of Neurosurgery: Pediatrics, 5, 30-48. https://doi.org/10.3171/2009.7.PEDS09215 


\section{List of Abbreviations}

$\mathrm{CP}$ Craniopharyngioma

ACP Adamantinoumatous Craniopharyngioma

PCP Papillary Craniopharyngioma

RCP Craniopharyngioma

CT Computed Tomography

MRI magnetic resonance imaging

OT Open Transcranial

TS Transsphenoidal

PTE Pterional

Tcall Transcallosal

Tcort Transcortical

EOR Extent of resection

GTR Gross total removal

STR Subtotal removal

RT Radiation therapy

GKS Gamma knife surgery

SRS Stereotactic radiosurgery

RR Recurrence Rate

RCTs Randomized control trials

GHRT Growth hormone replacement therapy

H.E Hematoxylin and Eosin Staining 